\title{
JOINT FINANCING AND ORDERING DECISIONS IN A CAPITAL-CONSTRAINED SUPPLY CHAIN WITH RISK PREFERENCE
}

\author{
ZHIYUAN ZHEN ${ }^{1, *}$ AND JingRU WANG ${ }^{2}$
}

\begin{abstract}
We consider a two-echelon supply chain consisting of one dominant supplier and one capital-constrained retailer. The retailer needs to solve the shortage of working capital either from a bank or from its core supplier, which offers trade credit when it is also beneficial to itself. We assume the retailer is risk-averse behavior and the supplier has different risk preference behaviors that jointly model risk-averse, risk-neutral, and risk-taking. With a wholesale price contract, we incorporate each member's risk preference behavior into its objective function. Then we derive the optimal decisions in a Stackelberg game under bank credit financing and trade credit financing, respectively. We find that there exists a supplier's risk preference threshold that distinguishes financing scheme. When the supplier is a relatively higher risk preference, trade credit financing makes both the retailer and the supplier better off and is a unique financing equilibrium. Otherwise, the members prefer bank credit financing. Besides, the supplier with relatively higher risk preference behavior prefers the retailer with a low initial capital as a partner; the supplier with relatively lower risk preference behavior prefers the retailer with a higher initial capital level. The above theoretical results are verified by numerical analysis.
\end{abstract}

Mathematics Subject Classification. 35J20, 35J25, 35J60.

Received April 6, 2020. Accepted September 2, 2020.

\section{INTRODUCTION}

Working capital plays a significant role in making business decisions. However, limited working capital is a frequent constraint, especially for SMEs (small and medium-sized enterprises) compared with large enterprises [2]. Hence, it is very necessary to alleviate the working capital pressure of SMEs as the key component of the supply chain. In recent years, supply chain financing (SCF) as an effective means to solve the financing bottleneck of SMEs $[4,14]$. SCF has two main financing schemes, one is bank credit financing (BCF), which is the most traditional financing scheme. According to the research report on the financing of SMEs in China, bank loans to SMEs account for $37.8 \%$ of enterprise loans in 2017. The other is trade credit financing (TCF), which provides a delay in payment by a seller to its buyer for ordering products. In the 674 listed enterprises of the stock exchange in China from 2001 to 2007, nearly $9.1 \%$ of the total financing amount is obtained from TCF [5].

Keywords. Risk preference, initial capital, trade credit financing, bank credit financing, financing equilibrium.

1 School of Business Administration, Hunan University, Changsha, Hunan 410082, P.R. China.

2 School of Information and Mathematics, Yangtze University, Jingzhou, Hubei 434023, P.R. China.

*Corresponding author: zhenzhiy@126.com 
SCF activities inevitably bring SMEs bankruptcy risks. How to effectively choose a financing scheme has become an important issue faced by many SMEs. In June 2011, Zhejiang Tianshi electronics company could not repay 50 million yuan to the bank and declared bankruptcy. A similar situation also occurred in the bankruptcy of SMEs such as Sanqi Group, Jiangnan Leather, and Portman. With the research on SMEs' operation decisions, the scholars find the managers don't always make decisions based on maximizing the expected profit and minimizing the expected cost when commercial risk exists [1]. Payne et al. [25] show empirical evidence that needs to incorporate aspiration target level into the analysis of the risk behavior decision. In addition, a survey of 1500 managers in 90 countries shows that even if the proposed project's expected profit is positive, the extreme risk-averse managers aren't interested in entering the market [20]. Hence, many scholars have begun to break through the traditional assumption that the supply chain members are risk-neutral behavior [32]. Tsay [31] implies that the supply chain members have different risk preferences when commercial risk exists. From the above empirical evidence, the supply chain member's risk preference behavior has an impact on the operation decisions of SMEs.

Based on the above business background, we attempt to investigate the interaction impact of initial capital and risk preference behavior on the supply chain's decisions under BCF and TCF. We focus on the following research questions. (1) How does the retailer's risk-averse behavior affect the supply chain members' operation decisions and performance? (2) How does the combination of initial capital and risk preference behavior affect the members' operation decisions and performance? (3) Which financing scheme will be preferred by both the supplier and the retailer? Is there a win-win financing scheme situation for each member?

To address these above research questions, we consider a two-echelon supply chain consisting of a dominant upstream supplier and a capital-constrained downstream retailer. The retailer's initial capital is insufficient to make its decisions, and needs to solve the shortage of working capital either from a bank or from its core supplier. We consider the retailer to be an SME that facing relatively higher bankruptcy risk compared with the supplier endowed with sufficient capital. The retailer is risk-averse and the supplier has different risk preferences. Then we model each member's risk preference behavior into its objective function, and derive the optimal decisions in a Stackelberg game under BCF and TCF, respectively. Further, we analyze the impact of the members' risk preference and initial capital on the financing decision, and reveal how the degree of risk preference behavior and initial capital affect the supply chain's decisions. Our analysis shows that there exists a supplier's risk preference threshold that distinguishes financing scheme. Besides, we also discuss the impact of the retailer's initial capital on the supply chain financing decision by numerical analysis. Finally, our analysis provides guidance for the capital-constrained supply chain's operation decisions.

The remainder of the paper is organized as follows. Section 2 introduces the related literature review. Section 3 describes the framework of our model. Section 4 presents separately the members' optimal decisions under BCF and TCF. Section 5 derives financing equilibrium under two financing schemes. The numerical analysis of the model is performed in Section 6. Section 7 gives the related conclusions and discussions of this paper. Finally, all proofs are presented in the Appendix A.

\section{LiterATURE REVIEW}

The literature review of the paper is surveyed from two aspects: supply chain financing and supply chain risk measurement.

\subsection{Supply chain financing}

Recently, SCF research mainly focuses on bank credit financing and trade credit financing. For example, the capital-constrained supply chain uses BCF to mitigate limited working capital pressure. Specifically, Kouvelis and Zhao [21] study the optimal decisions for a capital-constrained supply chain with bankruptcy costs under $\mathrm{BCF}$, and find that bankruptcy costs reduce the efficiency of the supply chain. Yan et al. [36] design an SCF including a bank and a capital-constrained retailer under an imperfect capital market and non-zero bankruptcy costs. Katehakis et al. [19] consider an SME's inventory management with BCF to satisfy uncertain demand, 
and propose the optimal decisions for maximizing the expected profit of SME. With the bank's risk attitude, Guo and Liu [16] investigate the effect of BCF on mass customization program. Moreover, many scholars also investigate the efficiency of TCF in a capital-constrained supply chain [37]. Chen and Wang [8] examine the optimal decisions for a capital-constrained supply chain with limited liability under TCF, and find that limited liability accounts for that the retailer with lower initial capital initiates a higher ordering level. Chang and Rhee [6] focus on the coordination in a capital-constrained supply chain with TCF and markdown allowance. Giri and Sharma [15] consider an inventory model under two-level TCF, in which the market demand is increasing linearly and the shortages are allowed. Qin et al. [27] explore the optimal decisions in a dual-channel supply chain under TCF. Furthermore, some scholars attempt to compare the efficiency of BCF and TCF to obtain an optimal financing scheme. To be more specific, Kouvelis and Zhao [22] explore the impact of working capital and collateral on a capital-constrained supply chain's financing equilibrium under BCF and TCF. Chen [7] studies financing equilibrium in a capital-constrained supply chain under BCF and TCF. Compared with the above literature, our paper falls into the interaction of initial capital and risk preference behavior to explore a capital-constrained supply chain's financing and ordering decisions.

\subsection{Supply chain risk measurement}

At present, the key measurement criteria of a member's risk-averse behavior are utility function, Meanvariance, VaR and CVaR (conditional value at risk) in the supply chain [40], where CVaR criterion is a coherent risk measure and consistent with a member perspective towards commercial risks $[11,28]$. In the supply chain risk measurement, CVaR criterion has been widely used in the newsvendor problem, coordination, and contract design [3]. Specifically, Chen et al. [10] study the optimal ordering and pricing decisions for a risk-averse newsvendor problem with multiplicative and additive stochastic demand, respectively. Xu et al. [34] explore the optimal decisions for a risk-averse newsvendor problem by minimizing the expected legacy loss, the CVaR of legacy loss, and the combination of expected legacy loss and CVaR of legacy loss. Under CVaR criterion, Shen et al. [30] study the coordination in a fashion clothing supply chain with a risk-averse supplier's discount subsidy policy, and investigate the impact of markdown subsidy policy on the supply chain decisions. Ye et al. [38] design a coordination contract in an agricultural supply chain with uncertain yield and demand. Yuan et al. [39] study the option contract strategies with risk-aversion and emergency purchases. Chen et al. [12] explore the coordination in a supply chain with a risk-averse manufacturer under TCF, and find that the supply chain coordination needs an extremely long credit period, while the quantity discount contract is insufficient to coordinate the supply chain. The above literature only considers the member's risk-averse behavior in the supply chain management. In order to characterize a supply chain member's different risk preference behaviors, Mean-CVaR criterion is proposed in [17], which is a convex combination of conditional expected values of low and high profits. Recently, many scholars have widely applied Mean-CVaR criterion to investigate the impact of the supply chain members' risk preference on the optimal decisions [13,24]. Xie et al. [33] study the coordination in a supply chain consisting of a retailer with different risk preferences and a risk-neutral supplier.

The closely related studies to this paper are Chen and Zhou [9] and Yan et al. [35]. Both papers discuss the optimal decisions in a capital-constrained supply chain under a single financing scheme, but there exist at least some differences from this paper. Chen and Zhou [9] discuss the optimal decisions in a capital-constrained supply chain with a risk-averse retailer and a risk-neutral supplier under TCF, and Yan et al. [35] discuss the optimal decisions in a capital-constrained supply chain with a risk-neutral retailer and a risk-averse supplier under BCF with the supplier's credit guarantee. This paper discusses the optimal decisions in a capital-constrained supply chain with a risk-averse retailer and a supplier has different risk preferences under TCF and BCF. In addition, we incorporate the member's risk preference and initial capital into its objective functions to explore the supply chain's financing and ordering decisions. 
TABLE 1. Notation and definition.

\begin{tabular}{ll}
\hline \hline Notation & Definition \\
\hline$p$ & Unit retail price. \\
$c$ & Unit production cost. \\
$B$ & Retailer's initial capital. \\
$w_{i}$ & Unit wholesale price, where $i=B, T$ represents \\
& two cases under BCF and TCF, respectively. \\
$q_{i}$ & Retailer's order quantity. \\
$x$ & Stochastic demand. \\
$\eta_{j}$ & Risk-averse coefficient, where $j=r, s$ represents \\
& the retailer and the supplier, respectively. \\
$\lambda_{s}$ & Supplier's pessimistic coefficient. \\
$\pi_{i}$ & Retailer's profit function. \\
$\Pi_{i}$ & Supplier's profit function. \\
$r_{f}$ & The risk-free interest rate. \\
$r_{B}$ & The interest rate charged by the bank. \\
$r_{T}$ & The interest rate charged by the supplier. \\
\hline
\end{tabular}

\section{MODEL DESCRIPTION}

We consider a two-echelon supply chain with a dominant upstream supplier (referred to as she) and a capitalconstrained downstream retailer (referred to as he). The retailer's initial capital $B$ is insufficient to make his operation decisions. The retailer has two financing schemes to mitigate the pressure of limited working capital: from BCF or from TCF, which the supplier provides TCF if it is also beneficial to herself. We consider the retailer to be a risk-averse SME that facing relatively higher bankruptcy risk. In order to make the model more general, we assume the supplier has different risk preferences that jointly model risk-averse, risk-neutral, and risk-taking. Let the parameter $\eta_{j} \in(0,1]$ denote the degree of the member's risk aversion. A smaller $\eta_{j}$ means a higher degree of risk aversion.

With a wholesale price contract, we establish a Stackelberg game model in which the supplier acts as a leader and the retailer acts as a follower under BCF and TCF. The sequence of events is as follows: the supplier decides a wholesale price $w_{i}$. Then the retailer decides order quantity $q_{i}$, and deals with the shortage of working capital by BCF or TCF. Under BCF, the bank charges the retailer an interest rate $r_{B}$, which is determined by a fully competitive bank market $[8,18,22,26]$. Under TCF, the supplier charges the retailer an interest rate $r_{T}$. In addition, the supplier ensures the retailer's profit under TCF is not less than that under BCF [7], which is consistent with the firm's financing selection based on its profit.

The market demand is stochastic which is denoted by $x \geq 0$. The probability density function is $f(x)$ and cumulative distribution function is $F(x)$, respectively. $F(x)$ is differentiable, increasing, $F(0)=0$ and $F(\infty)=1$; its failure rate $h(x)=\frac{f(x)}{F(x)}$ is increasing in $x$, where $\bar{F}(x)=1-F(x) ; H(x)=x h(x)$ is the generalized failure rate and monotonically increasing in $x[7,18]$. Without loss of generality, we assume that the products have no salvage and $p \geq w_{i}\left(1+r_{i}\right) \geq c\left(1+r_{f}\right)>0$ [21-23]. Table 1 summarizes the notations in this paper.

\section{BANK OR TRADE CREDIT FINANCING}

In this section, we investigate the equilibrium results of the risk-averse retailer and the supplier with different risk preferences under $\mathrm{BCF}$ and $\mathrm{TCF}$, respectively. 


\subsection{Bank credit financing}

At the beginning of the selling season, the supplier decides a wholesale price $w_{B}$. The retailer decides an order quantity $q_{B}$, and borrows the shortage of working capital $\left(w_{B} q_{B}-B\right)$ from a fully competitive bank at an interest rate $r_{B}$. Then the retailer pays $w_{B} q_{B}$ to the supplier for ordering products. At the end of the selling season, the retailer yields revenue $p \min \left(q_{B}, x\right)$, and needs to repay the bank loans and interest of $\left(w_{B} q_{B}-B\right)\left(1+r_{B}\right)$. If $p \min \left(q_{B}, x\right) \geq\left(w_{B} q_{B}-B\right)\left(1+r_{B}\right)$, the retailer repays $\left(w_{B} q_{B}-B\right)\left(1+r_{B}\right)$ to the bank. Otherwise, the retailer goes bankrupt, and must repay all of his revenue $p \min \left(q_{B}, x\right)$ to the bank. To obtain the equilibrium solutions, we use the backward method to solve the Stackelberg game model. Based on a fully competitive bank market, the bank's interest rate $r_{B}^{*}$ satisfies

$$
\left(w_{B} q_{B}-B\right)\left(1+r_{f}\right)=E\left[\min \left\{p \min \left(q_{B}, x\right),\left(w_{B} q_{B}-B\right)\left(1+r_{B}^{*}\right)\right\}\right],
$$

where $r_{B}^{*}$ satisfies $r_{B}^{*} \geq r_{f}$ to compensate the bank for the loss of the retailer's bankruptcy risk.

According to the bank's interest rate $r_{B}^{*}$, the retailer's profit function is given by $\pi_{B}\left(q_{B}, x\right)=\left[p \min \left(q_{B}, x\right)-\right.$ $\left.\left(w_{B} q_{B}-B\right)\left(1+r_{B}^{*}\right)\right]^{+}-B\left(1+r_{f}\right)$, where $[y]^{+}=\max (y, 0)$ and $x_{B}=\frac{\left(w_{B} q_{B}-B\right)\left(1+r_{B}^{*}\right)}{p}$ is the retailer's bankruptcy threshold. To analyze the impact of the risk aversion behavior on the retailer's decision, we adopt CVaR criterion to incorporate his risk-averse behavior into the profit function. Hence, the risk-averse retailer's objective function under CVaR criterion is

$$
\operatorname{CVaR}_{\eta_{r}}\left(\pi_{B}\left(q_{B}, x\right)\right)=\max _{v \in R}\left\{v-\frac{1}{\eta_{r}} E\left[v-\pi_{B}\left(q_{B}, x\right)\right]^{+}\right\} .
$$

The following proposition establishes the risk-averse retailer's optimal ordering decision in the decentralized system under BCF.

Proposition 4.1. Under BCF, (i) the risk-averse retailer's optimal order quantity $q_{B}^{*}=\bar{F}^{-1}\left(\left(1-\eta_{r}\right)+\left(\eta_{r}-F\left(x_{B}^{*}\right)\right) \frac{w_{B}\left(1+r_{f}\right)}{p \bar{F}\left(x_{B}^{*}\right)}\right)$; (ii) $\frac{\partial q_{B}^{*}}{\partial w_{B}}<0, \frac{\partial q_{B}^{*}}{\partial \eta_{r}}>0$ and $\frac{\partial q_{B}^{*}}{\partial B}<0$.

Under BCF, when $\eta_{r} \in(0,1)$ (i.e., risk-averse), the capital-constrained retailer transfers partially commercial risks to the bank, but the capital-unconstrained retailer has to bear full commercial risks. Therefore, the capitalconstrained retailer's optimal order quantity under BCF is more than that of the capital-unconstrained retailer. This result is different for the risk-neutral and capital-constrained retailer [7, 18,22]. To more specific, when $\eta_{r}=1$ (i.e., risk-neutral), due to a fully competitive bank market, the bank plays the role of a money buffer at no cost for the capital-constrained retailer. Hence, the capital-constrained retailer's optimal order quantity is the same as that of the capital-unconstrained retailer. This is identical to the findings in $[7,18,22]$. Besides, a lower risk-averse coefficient means that the retailer is more sensitive to avoid commercial risks than to pursue higher profits. The retailer further reduces his order quantity to avoid commercial risks. As the risk-averse retailer's initial capital increases, the retailer bears more commercial risks, thereby the lower products his orders. However, when the retailer is risk-neutral, the retailer's initial capital does not influence his order quantity under BCF.

At the beginning of the selling season, the retailer pays the supplier $w_{B} q_{B}^{*}$. With a wholesale price contract, the supplier with different risk preferences under BCF does not bear any commercial risks. Therefore, the supplier's objective function under Mean-CVaR criterion is

$$
U\left(\Pi_{B}\left(w_{B}\right)\right)=\Pi_{B}\left(w_{B}\right)=\left(w_{B}-c\right) q_{B}^{*}\left(1+r_{f}\right) .
$$

The following proposition establishes the supplier's optimal wholesale price in the decentralized system under $\mathrm{BCF}$.

Proposition 4.2. Under BCF, the optimal wholesale price $w_{B}^{*}=\frac{p q_{B}^{*} f\left(q_{B}^{*}\right)+\mu_{1}\left(w_{B}^{*}\right) c\left(1+r_{f}\right)}{\left(\eta_{r}-F\left(x_{B}^{*}\right)\right)\left(1+r_{f}\right)} \bar{F}\left(x_{B}^{*}\right)$, where $\mu_{1}\left(w_{B}^{*}\right)=1-\frac{1-\eta_{r}}{\bar{F}\left(x_{B}^{*}\right)}-\frac{\left(1-\eta_{r}\right) w_{B}^{*} q_{B}^{*}\left(1+r_{f}\right)}{p\left(\bar{F}\left(x_{B}^{*}\right)\right)^{2}} h\left(x_{B}^{*}\right)$. 
Proposition 4.2 implies that the supplier's optimal wholesale price does not depend on her risk preference behavior under BCF, and only depends on her retailer's initial capital and degree of risk aversion. To gain more profits, the supplier will adjust her wholesale price to affect the risk-averse retailer's ordering decision. For example, as the retailer's initial capital increases, the supplier reduces the wholesale price to promote the retailer to order more products.

\subsection{Trade credit financing}

At the beginning of the selling season, the supplier decides a wholesale price $w_{T}$, and then the retailer decides an order quantity $q_{T}$. At the end of the selling season, the retailer yields revenue $p \min \left(q_{T}, x\right)$, and needs to repay the supplier's loans and interest of $\left(w_{T} q_{T}-B\right)\left(1+r_{T}\right)$. If $p \min \left(q_{T}, x\right)\left(w_{T} q_{T}-B\right)\left(1+r_{T}\right)$, the retailer repays $\left(w_{T} q_{T}-B\right)\left(1+r_{T}\right)$ to the supplier. Otherwise, the retailer goes bankrupt, and must repay all of his revenue $p \min \left(q_{T}, x\right)$ to the supplier, Therefore, the retailer's profit function is $\pi_{T}\left(q_{T}, x\right)=\left[p \min \left(q_{T}, x\right)-\left(w_{T} q_{T}-\right.\right.$ $\left.B)\left(1+r_{T}\right)\right]^{+}-B\left(1+r_{f}\right)$, where $x_{T}=\frac{\left(w_{T} q_{T}-B\right)\left(1+r_{T}\right)}{p}$ is the retailer's bankruptcy threshold. The risk-averse retailer's objective function under CVaR criterion is as follows

$$
\mathrm{CVaR}_{\eta_{r}}\left(\pi_{T}\left(q_{T}, x\right)\right)=\max _{v \in R}\left\{v-\frac{1}{\eta_{r}} E\left[v-\pi_{T}\left(q_{T}, x\right)\right]^{+}\right\} .
$$

The following proposition establishes the risk-averse retailer's optimal ordering decision in the decentralized system under TCF.

Proposition 4.3. Under TCF, (i) the risk-averse retailer's optimal order quantity $q_{T}^{*}=\bar{F}^{-1}\left(\left(1-\eta_{r}\right)+\left(\eta_{r}-F\left(x_{T}^{*}\right)\right) \frac{w_{T}\left(1+r_{T}\right)}{p}\right)$; (ii) $\frac{\partial q_{T}^{*}}{\partial w_{T}}<0, \frac{\partial q_{T}^{*}}{\partial \eta_{r}}>0$ and $\frac{\partial q_{T}^{*}}{\partial B}<0$.

Under TCF, the supplier is not only a producer but also an investor. The supplier has to bear the retailer's partial bankruptcy risks and the whole production costs. The lower bound of the supplier's wholesale price $\underline{w}_{T}$ ensures that the marginal profit of the supplier exceeds or equals her marginal cost under Mean-CVaR criterion. Besides, the upper bound of wholesale price $\bar{w}_{T}$ satisfies $\operatorname{CVaR}_{\eta_{r}}\left(\pi_{T}\left(\bar{w}_{T}\right)\right)=\operatorname{CVaR}_{\eta_{r}}\left(\pi_{B}\left(w_{B}^{*}\right)\right)$. Therefore, the wholesale price's feasible region satisfies $\left[\underline{w}_{T}, \bar{w}_{T}\right]$. Proposition 4.3 shows as the wholesale price increases, the retailer uses TCF becomes more costly, thereby reducing his order quantity. Moreover, the capital-constrained retailer's marginal cost is less than that of the capital-unconstrained retailer. Hence, the capital-constrained retailer's optimal order quantity will be more than of the capital-unconstrained retailer. Moreover, the more the retailer's initial capital is, the lower quantity the retailer orders. This is because the retailer reduces his order quantity to avoid commercial risks.

At the end of the selling season, the retailer needs to repay the supplier $\lim \left\{p \min \left(q_{T}^{*}, x\right),\left(w_{T} q_{T}^{*}-B\right)\left(1+r_{T}\right)\right\}$. The supplier's profit function is given by $\Pi_{T}\left(w_{T}\right)=\min \left\{p \min \left(q_{T}^{*}, x\right),\left(w_{T} q_{T}^{*}-B\right)\left(1+r_{T}\right)\right\}-c q_{T}^{*}\left(1+r_{f}\right)+$ $B\left(1+r_{f}\right)$. To analyze the impact of the risk preference behavior on the supplier's decision, we adopt Mean-CVaR criterion to incorporate the supplier's risk preference behavior into her profit function. Hence, the supplier's objective function under Mean-CVaR criterion is

$$
U\left(\Pi_{T}\left(w_{T}\right)\right)=\frac{1-\lambda_{s}}{1-\eta_{s}} E\left(\Pi_{T}\left(w_{T}\right)\right)+\frac{\lambda_{s}-\eta_{s}}{1-\eta_{s}} \operatorname{CVaR}_{\eta_{s}}\left(\Pi_{T}\left(w_{T}\right)\right),
$$

where $U\left(\Pi_{T}\left(w_{T}\right)\right)$ is a convex combination of conditional expected values of low and high profits. The convex combination is described by the pessimistic coefficient $\lambda_{s} \in[0,1]$. The higher $\lambda_{s}$ is, the weight the supplier puts to the low profits.

Based on the supplier's objective function, the following proposition establishes the supplier's optimal wholesale price in the decentralized system under TCF.

Proposition 4.4. Under TCF, when $B=0$, the optimal wholesale price $w_{T}^{*}=\underline{w}_{T}$. When $B>0$, if $\eta_{s} \in\left(0, F\left(x_{T}^{*}\right)\right)$, the optimal wholesale price $w_{T}^{*}=\min \left\{\max \left\{\underline{w}_{T}, \hat{w}_{T}\right\}, \bar{w}_{T}\right\}$, 
where $\hat{w}_{T}=\frac{\left(1-\eta_{s}\right) c\left(1+r_{f}\right)-p\left(1-\eta_{r}\right)\left(1-\lambda_{s}\right) \mu_{2}\left(\hat{w}_{T}\right)}{\left(\eta_{r}-F\left(x_{T}^{*}\right)\right)\left(1+r_{T}\right)\left(1-\lambda_{s}\right) \mu_{2}\left(\hat{w}_{T}\right)}$

if $\eta_{s} \in\left[F\left(x_{T}^{*}\right), 1\right]$, the optimal wholesale price $w_{T}^{*}=\min \left\{\max \left\{\underline{w}_{T}, \tilde{w}_{T}\right\}, \bar{w}_{T}\right\}$,

where $\tilde{w}_{T}=\frac{\eta_{s} F\left(x_{T}^{*}\right) c\left(1+r_{f}\right)-p\left(1-\eta_{r}\right)\left(\eta_{s}-\lambda_{s} F\left(x_{T}^{*}\right)\right) \mu_{2}\left(\tilde{w}_{T}\right)}{\left(\eta_{r}-F\left(x_{T}^{*}\right)\right)\left(1+r_{T}\right)\left(\eta_{s}-\lambda_{s} F\left(x_{T}^{*}\right)\right) \mu_{2}\left(\tilde{w}_{T}\right)}$ and $\mu_{2}\left(w_{T}\right)=\frac{1-\frac{1-\eta_{r}}{F\left(q_{T}^{*}\right)}-H\left(q_{T}^{*}\right)}{1-\frac{1-\eta_{r}}{F\left(x_{T}^{*}\right)}-\frac{w_{T} q_{T}^{*}\left(1+r_{T}\right)}{p} h\left(x_{T}^{*}\right)}$.

Under TCF, when $B=0$, the risk-averse retailer's bankruptcy risks fully transfer to the supplier. The supplier further increases the wholesale price to compensate for the loss caused by the bankruptcy of the retailer. Hence, the supplier's optimal wholesale price $w_{T}^{*}=\underline{w}_{T}$. When $B>0$, the retailer needs to bear partial bankruptcy risks. From Proposition 4.4, the more the retailer's initial capital is, the more commercial risks the retailer bears. Moreover, we observe that the supplier's risk preference behavior affects her optimal wholesale price. When the supplier is risk-averse, the supplier is more sensitive to avoid commercial risks than to pursue higher profits. Then the supplier increases her wholesale price to avoid more commercial risks. Otherwise, the supplier reduces her wholesale price to promote the retailer to order more.

\section{FinANCING STRATEGY}

In the previous section, we obtain the equilibrium solutions in the Stackelberg game under BCF and TCF, respectively. The above analysis naturally leads to a problem for the capital-constrained and risk-averse retailer, that is, how to make an effective financing decision. Note that a special result whether the capital-constrained and risk-averse retailer only chooses TCF, due to the supplier ensures that the retailer's profit under TCF is not less than that of the retailer under BCF. However, the supplier can decide whether to provide TCF for the retailer based on her profit. Proposition 5.1 reveals a financing strategy with the supplier's risk preference.

Proposition 5.1. If $\lambda_{s} \in\left[0, \bar{\lambda}_{s}\right)$, TCF is unique financing equilibrium; if $\lambda_{s} \in\left[\bar{\lambda}_{s}, 1\right]$ the members prefer $B C F$, where $\bar{\lambda}_{s}=\min \left(\bar{\lambda}_{s}\left(\eta_{s}\right), 1\right)$ and

$$
\bar{\lambda}_{s}\left(\eta_{s}\right)=\left\{\begin{array}{lll}
1-\left(1-\eta_{s}\right) \frac{\left(w_{B}^{*} q_{B}^{*}-c q_{B}^{*}-B+c q_{T}^{*}\right)\left(1+r_{f}\right)-p F^{-1}\left(\eta_{s}\right)+\frac{p}{\eta_{s}} \int_{0}^{F^{-1}\left(\eta_{s}\right)} F(x) \mathrm{d} x}{\left(w_{T}^{*} q_{T}^{*}-B\right)\left(1+r_{T}\right)-p \int_{0}^{* *} F(x) \mathrm{d} x-p F^{-1}\left(\eta_{s}\right)+\frac{p}{\eta_{s}} \int_{0}^{F^{-1}\left(\eta_{s}\right)} F(x) \mathrm{d} x}, & \text { if } & \eta_{s}<F\left(x_{T}^{*}\right) \\
\eta_{s} \frac{\left(w_{T}^{*} q_{T}^{*}-B\right)\left(1+r_{T}\right)-c\left(q_{T}^{*}-q_{B}^{*}\right)\left(1+r_{f}\right)-\left(w_{B}^{*} q_{B}^{*}-B\right)\left(1+r_{f}\right)}{p \int_{0}^{x_{T}^{*}} F(x) \mathrm{d} x}, & \text { if } & \eta_{s} \geq F\left(x_{T}^{*}\right) .
\end{array}\right.
$$

Under BCF, the supplier with different risk preferences under BCF does not bear any commercial risks. Then the supplier's Mean-CVaR is not influenced by her risk preference behavior. Under TCF, we show the supplier's Mean-CVaR is decreasing in $\lambda_{s}$. Correspondingly, there exists a supplier pessimistic coefficient $\bar{\lambda}_{s}\left(\eta_{s}\right)$ satisfies $U\left(\Pi_{T}\left(w_{T}^{*}\right)\right)=U\left(\Pi_{B}\left(w_{B}^{*}\right)\right)$. Based on the proof of Proposition 5.1, we have the supplier's pessimistic coefficient threshold $\bar{\lambda}_{s}=\min \left(\bar{\lambda}_{s}\left(\eta_{s}\right), 1\right)$. Hence, if the supplier's pessimistic coefficient is less than $\bar{\lambda}_{s}$, the supplier provides TCF for the retailer. Then TCF makes both the retailer and the supplier better off, and is the financing equilibrium of the supply chain. Otherwise, the members prefer BCF.

Next, we explore the impact of the retailer's initial capital on the financing equilibrium of the supply chain. Under stochastic market demand, the retailer is risk-averse behavior and the supplier has different risk preferences that jointly model risk-averse, risk-neutral, and risk-taking. Due to the complexity of comparing BCF and TCF analytically, we numerically illustrate the financing equilibrium with the retailer's initial capital. Similar to Chen and Zhou [9], the parameter settings are as follows: $x \sim N\left(100,150^{2}\right), p=100, c=20$, $r_{T}=0.05, r_{f}=0, \eta_{r}=0.6, \lambda_{s}=0.6$ and $\eta_{s}=0.8$. Figure 1 shows the capital-constrained retailer's CVaR is increasing in $B$, and the supplier's Mean-CVaR is decreasing in $B$. In addition, Figure 1 also illustrates the supply chain's financing strategy in the interval region of $B$. When $B \in(0, \bar{B})$, TCF is a unique financing equilibrium; when $B \in(\bar{B}, 6000)$, the retailer only chooses BCF. Moreover, there exists a $\underline{B}$ so that $\operatorname{CVaR}_{\eta_{r}}\left(\pi_{T}(\underline{B})\right)=\operatorname{CVaR}_{\eta_{r}}\left(\pi_{B}(\underline{B})\right)$. Furthermore, there exists a Pareto improvement region $B \in(\underline{B}, \bar{B})$ under $\mathrm{TCF}$, which is a win-win financing scheme situation for each member. 


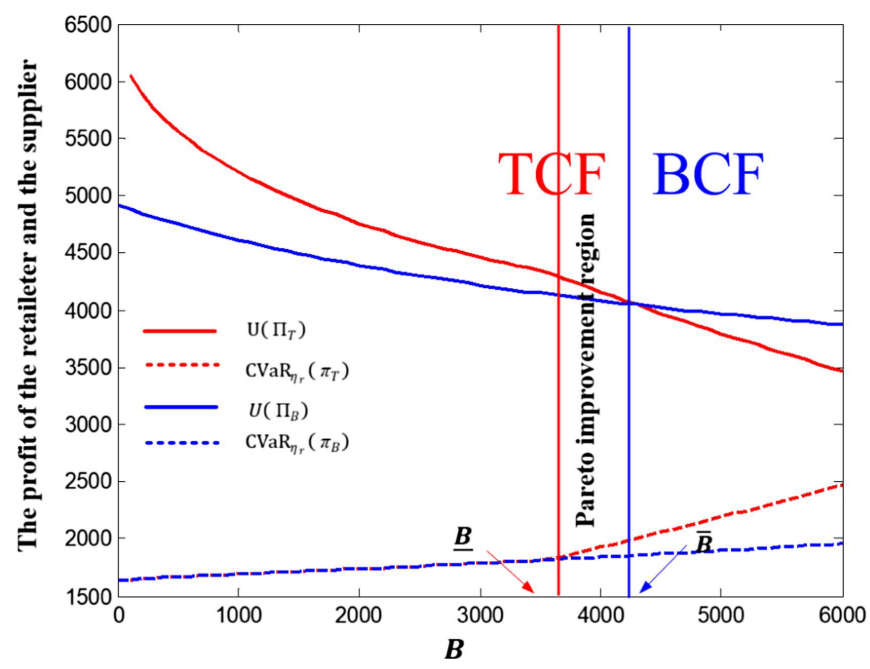

Figure 1. The profit of the members with $B$.

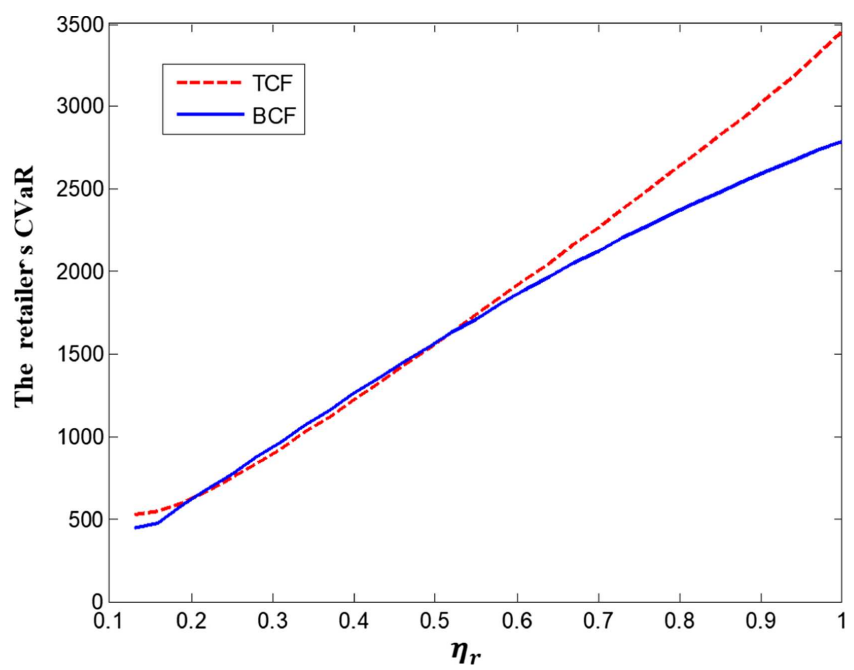

FiguRE 2. The retailer's CVaR with $\eta_{r}$.

\section{NUMERICAL ANALYSIS}

In this section, numerical analysis is used to verify the above theoretical results. The parameter settings are as follows: $x \sim N\left(100,150^{2}\right), p=100, c=20, r_{s}=0.05, r_{f}=0$ and $B=1000$. The stochastic variable $x \sim N\left(100,150^{2}\right)$, which satisfies the property of failure rate and generalized failure rate. When the stochastic variable $x$ satisfies certain conditions, the normal distribution can transform other distributions, such as uniform distribution, exponential distribution. In addition, we set $p=100$ and $c=20$, which satisfy our above assumption $p \geq w_{i}\left(1+r_{i}\right) \geq c\left(1+r_{f}\right)>0$. In order to meet the real business situation and our assumption $w_{i} q_{i} \geq B$, we set $B=1000$. Without loss of generality, we set $r_{T}=0.05$ and $r_{f}=0$.

Figure 2 illustrates the impact of $\eta_{r}$ on the risk-averse retailer's CVaR under BCF and TCF. Figure 2 shows the risk-averse retailer's CVaR is increasing in $\eta_{r}$ under BCF and TCF, which is consistent with Propositions 4.1(ii) 


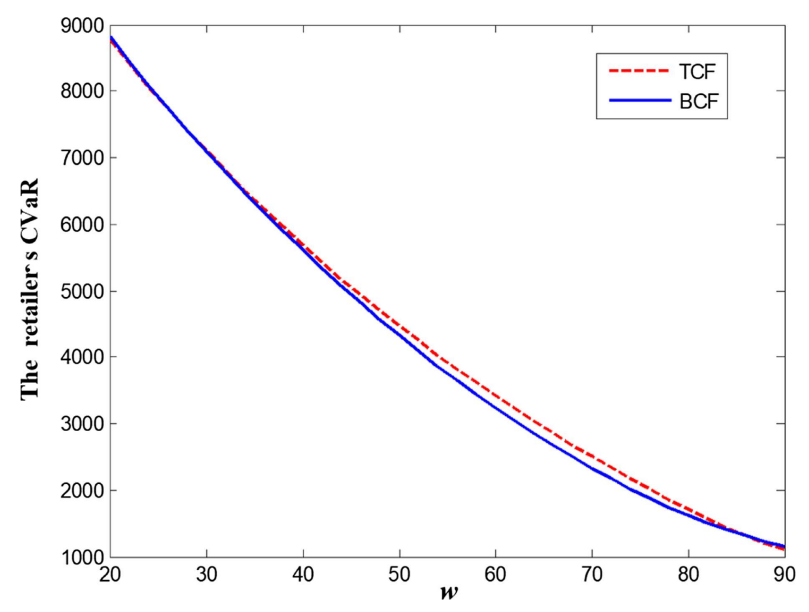

Figure 3. The retailer's CVaR with $w$.

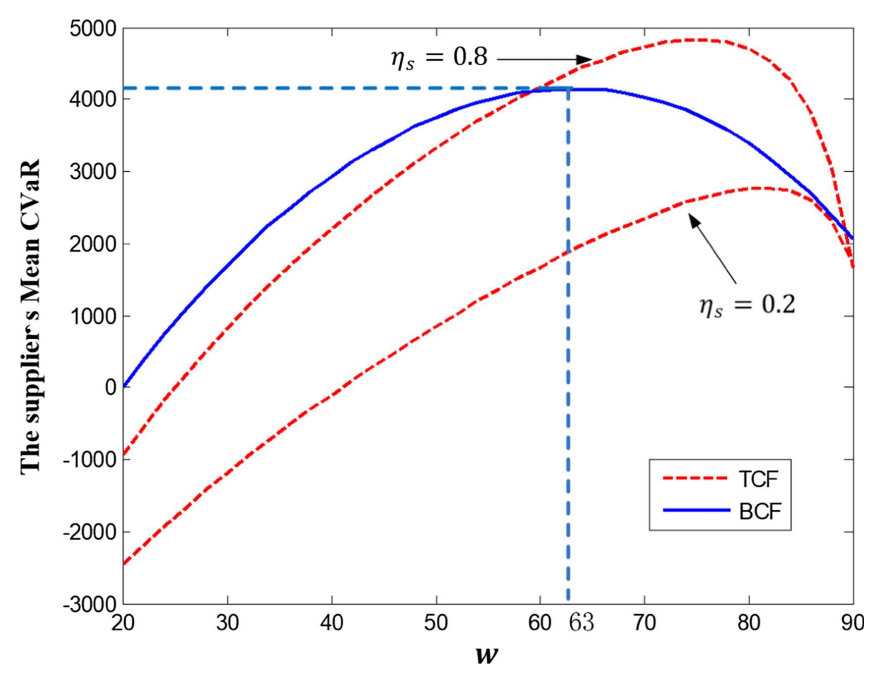

Figure 4. The supplier's Mean-CVaR with $w$.

and 4.3(ii). In addition, the retailer's order quantity is more sensitive to its risk-averse behavior under TCF than under BCF.

Taking $\eta_{r}=0.6$, we study the impact of $w$ on the risk-averse retailer's CVaR under BCF and TCF. Figure 3 shows the retailer's CVaR is decreasing in $w$ under two financing schemes, which is consistent with Propositions 4.1(ii) and 4.3(ii).

Taking $\lambda_{s}=0.6, \eta_{s}=0.2$ and $\lambda_{s}=0.6, \eta_{s}=0.8$, respectively. We study the impact of $\mathrm{w}$ on the supplier's Mean-CVaR under BCF and TCF. Figure 4 shows the Mean-CVaR of the supplier with $\eta_{s}=0.2$ under TCF is less than that under BCF. Therefore, the supplier does not provide TCF, the members prefer BCF. The Mean-CVaR of the supplier with $\eta_{s}=0.8$ under TCF is more than that under BCF, the supplier prefers to provide TCF, then TCF is financing equilibrium.

Taking $B=4000$ and $B=1000$, respectively. We study the impact of the supplier's risk preference on the supply chain's financing strategy under BCF and TCF. Figures 5 and 6 show the supplier's Mean-CVaR under 


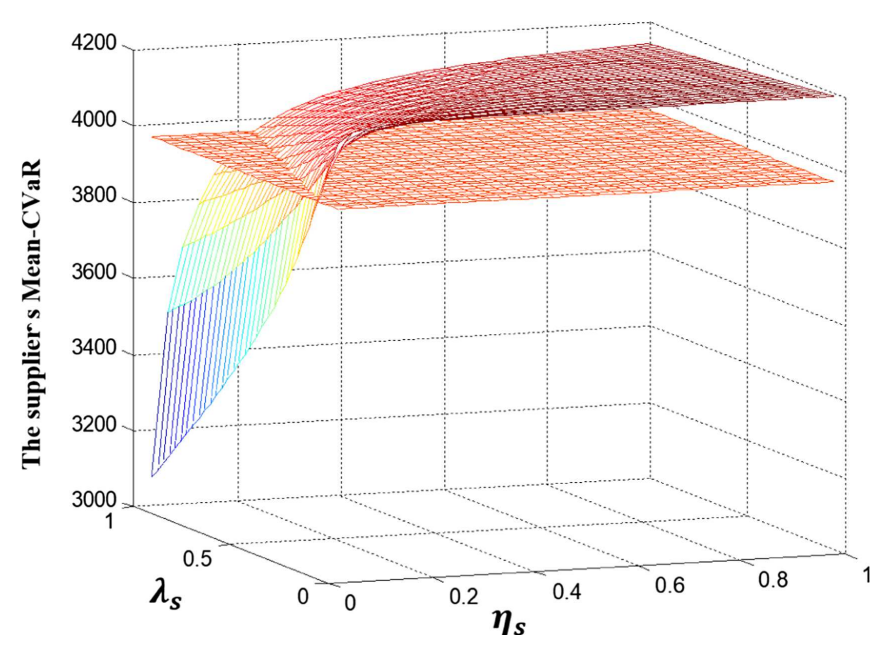

Figure 5. The supplier's Mean-CVaR with $\eta_{s}$ and $\lambda_{s}$.

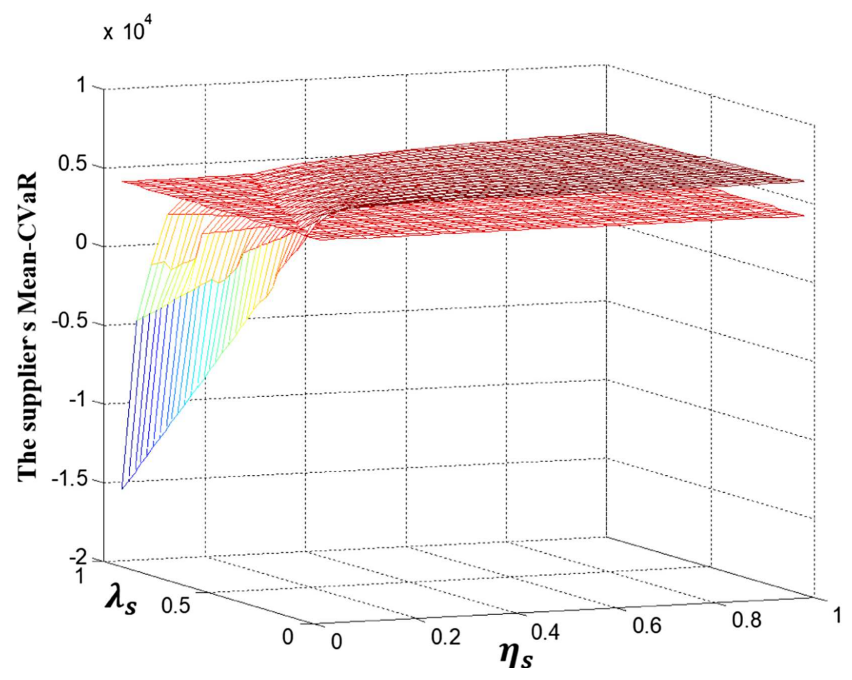

Figure 6. The supplier's Mean-CVaR with $\eta_{s}$ and $\lambda_{s}$.

BCF is not influenced by her risk preference behavior; the supplier's Mean-CVaR under TCF is decreasing in $\lambda_{s}$. In addition, Figures 5 and 6 show there exists a supplier's pessimistic coefficient threshold $\bar{\lambda}_{s}\left(\eta_{s}\right)$ such that $U\left(\Pi_{T}\left(w_{T}^{*}\right)\right)=U\left(\Pi_{B}\left(w_{B}^{*}\right)\right)$. In addition, by comparing Figures 5 and 6 , we find that the retailer's initial capital $B$ affects the supplier's risk preference threshold.

\section{Discussion AND CONCLUSION}

In this paper, we consider a two-echelon supply chain consisting of a dominant supplier and a capitalconstrained retailer, where the retailer is risk-averse and the supplier has different risk preferences. With a wholesale price contract, we use CVaR and Mean-CVaR criterion to incorporate each member's risk preference into its objective function, and derive the optimal decisions under BCF and TCF. The results show that: First, the risk-averse and capital-constrained retailer's optimal order quantity is more than that of the risk-averse 
and capital-unconstrained retailer, and decreasing in his degree of risk aversion. Second, the retailer's initial capital can make his order decision more conservative. Third, there exists a supplier's risk preference coefficient threshold that affects the financing equilibrium. When the supplier's pessimistic coefficient is less than the threshold, TCF is a unique financing equilibrium. Otherwise, the members prefer bank credit financing. Finally, the retailer's initial capital affects the supply chain's financing strategy.

The management implications of the paper are as follows: First, the risk-averse and capital-constrained retailer needs to consider choosing the supplier with a relatively higher risk preference as a partner to obtain higher profits. Second, the supplier needs to consider choosing a retailer with relatively lower risk aversion as much as possible to pursue higher profits. However, note that the supplier will face a higher commercial risk, and needs to pay attention to control the issues of the commercial risks. Third, the supplier has a relatively higher risk preference behavior prefers the retailer with lower initial capital as a partner; the supplier has a relatively lower risk preference behavior prefers the retailer with a higher initial capital level. There are two directions for further research. First, in our proposed model, we focus on the financing and ordering decisions in a capital-constrained supply chain under BCF and TCF. In a real-world business, there widely exists equity financing. Incorporating equity financing in our model will discover more interesting results. Second, compared with the upstream supplier, the downstream retailer has a better understanding of market demand information. Hence, information asymmetry in the supply chain will be an interesting topic in feature research.

Acknowledgements. The research is supported by the Postgraduate Scientific Research Innovation Project of Hunan Province under Grant No. CX20200456.

\section{Appendix A.}

Proof of Proposition 4.1. (i) Under BCF, the risk-averse retailer's objective function under CVaR criterion is

$$
\mathrm{CVaR}_{\eta_{r}}\left(\pi_{B}\left(q_{B}, x\right)\right)=\max _{v \in R}\left\{v-\frac{1}{\eta_{r}} E\left[v-\pi_{B}\left(q_{B}, x\right)\right]^{+}\right\}=\max _{v \in R}\left\{g\left(q_{B}, v\right)\right\}
$$

then $q_{B}^{*}=\arg \max _{q_{B}>0}\left\{\mathrm{CVaR}_{\eta_{r}}\left(\pi_{B}\left(q_{B}, x\right)\right)\right\}$. Thus $g\left(q_{B}, v\right)=v-\frac{1}{\eta_{r}} E\left[v-\pi_{B}\left(q_{B}, x\right)\right]^{+}=v-\frac{1}{\eta_{r}} \int_{0}^{x_{B}}[v+B(1+$ $\left.\left.r_{f}\right)\right]^{+} \mathrm{d} F(x)-\frac{1}{\eta_{r}} \int_{x_{B}}^{q_{B}}\left[v-p x+\left(w_{B} q_{B}-B\right)\left(1+r_{B}^{*}\right)+B\left(1+r_{f}\right)\right]^{+} \mathrm{d} F(x)-\frac{1}{\eta_{r}} \int_{q_{B}}^{\infty}\left[v-p q_{B}+\left(w_{B} q_{B}-B\right)(1+\right.$ $\left.\left.r_{B}^{*}\right)+B\left(1+r_{f}\right)\right]^{+} \mathrm{d} F(x)$, where $x_{B}=\frac{\left(w_{B} q_{B}-B\right)\left(1+r_{B}^{*}\right)}{p}$. We have the following three cases.

Case 1. If $v \leq-B\left(1+r_{f}\right)$, then $g\left(q_{B}, v\right)=v$, hence $\frac{\partial g\left(q_{B}, v\right)}{\partial v}=1>0$.

Case 2. If $-B\left(1+r_{f}\right)<v \leq p q_{B}-\left(w_{B} q_{B}-B\right)\left(1+r_{B}^{*}\right)-B\left(1+r_{f}\right)$, then $g\left(q_{B}, v\right)=v-\frac{1}{\eta_{r}} \int_{0}^{x_{B}}\left(v+B\left(1+r_{f}\right)\right) \mathrm{d} F(x)-\frac{1}{\eta_{r}} \int_{x_{B}}^{\frac{v+B\left(1+r_{f}\right)+\left(w_{B} q_{B}-B\right)\left(1+r_{B}^{*}\right)}{p}}\left(v-p x+\left(w_{B} q_{B}-B\right)\right.$ $\left.\left(1+r_{B}^{*}\right)+B\left(1+r_{f}\right)\right) \mathrm{d} F(x)$, hence $\frac{\partial g\left(q_{B}, v\right)}{\partial v}=1-\frac{1}{\eta_{r}} F\left(\frac{v+B\left(1+r_{f}\right)+\left(w_{B} q_{B}-B\right)\left(1+r_{B}^{*}\right)}{p}\right)$. Thus $\left.\frac{\partial g\left(q_{B}, v\right)}{\partial v}\right|_{v=-B\left(1+r_{f}\right)}=1-\frac{1}{\eta_{r}} F\left(x_{B}\right)$ and $\left.\frac{\partial g\left(q_{B}, v\right)}{\partial v}\right|_{v=p q_{B}-\left(w_{B} q_{B}-B\right)\left(1+r_{B}^{*}\right)-B\left(1+r_{f}\right)}=1-\frac{1}{\eta_{r}} F\left(q_{B}\right)$.

Case 3. If $v>p q_{B}-\left(w_{B} q_{B}-B\right)\left(1+r_{B}^{*}\right)-B\left(1+r_{f}\right)$, then $g\left(q_{B}, v\right)=v-\frac{1}{\eta_{r}} \int_{0}^{x_{B}}$ $\left(v+B\left(1+r_{f}\right)\right) \mathrm{d} F(x)-\frac{1}{\eta_{r}} \int_{x_{B}}^{q_{B}}\left(v-p x+\left(w_{B} q_{B}-B\right)\left(1+r_{B}^{*}\right)+B\left(1+r_{f}\right)\right) \mathrm{d} F(x)-\frac{1}{\eta_{r}} \int_{q_{B}}^{\infty}\left(v-p q_{B}+\right.$ $\left.\left(w_{B} q_{B}-B\right)\left(1+r_{B}^{*}\right)+B\left(1+r_{f}\right)\right) \mathrm{d} F(x)$, hence $\frac{\partial g\left(q_{B}, v\right)}{\partial v}=1-\frac{1}{\eta_{r}}<0$.

When $v^{*}=-B\left(1+r_{f}\right)$, then $0<\eta_{r} \leq F\left(x_{B}\right)$, we have $g\left(q_{B}, v^{*}\right)=-B\left(1+r_{f}\right)$. Thus $\frac{\partial g\left(q_{B}, v^{*}\right)}{\partial q_{B}}=0$. When $v^{*}=p F^{-1}\left(\eta_{r}\right)-\left(w_{B} q_{B}-B\right)\left(1+r_{B}^{*}\right)-B\left(1+r_{f}\right)$, then $F\left(x_{B}\right)<\eta_{r} \leq F\left(q_{B}\right)$, we have $g\left(q_{B}, v^{*}\right)=p F^{-1}\left(\eta_{r}\right)-\left(w_{B} q_{B}-B\right)\left(1+r_{B}^{*}\right)-B\left(1+r_{f}\right)-\frac{p}{\eta_{r}} \int_{x_{B}}^{F^{-1}\left(\eta_{r}\right)} F(x) \mathrm{d} x$. From a fully competitive bank market $[7,18,22,23]$, we obtain $\left(w_{B} q_{B}-B\right)\left(1+r_{f}\right)=\left(w_{B} q_{B}-B\right)\left(1+r_{B}^{*}\right)-$ $p \int_{0}^{x_{B}} F(x) \mathrm{d} x$, then $\frac{\partial x_{B}}{\partial q_{B}}=\frac{w_{B}\left(1+r_{f}\right)}{p \bar{F}^{-1}\left(x_{B}\right)}$.

Thus $\frac{\partial g\left(q_{B}, v^{*}\right)}{\partial q_{B}}=-p\left(1-\frac{F\left(x_{B}\right)}{\eta_{r}}\right) \frac{\partial x_{B}}{\partial q_{B}}<0$ and $\frac{\partial^{2} g\left(q_{B}, v^{*}\right)}{\partial\left(q_{B}\right)^{2}}=f\left(q_{B}\right)\left(\frac{w_{B}\left(1+r_{f}\right)}{p \bar{F}\left(x_{B}\right)}+\left(1-\frac{F\left(x_{B}\right)}{\eta_{r}}\right) \frac{w_{B}\left(1+r_{f}\right)}{\left(\bar{F}\left(x_{B}\right)\right)^{2}}\right) \frac{\partial x_{B}}{\partial q_{B}}>0$. 
When $v^{*}=p q_{B}-\left(w_{B} q_{B}-B\right)\left(1+r_{B}^{*}\right)-B\left(1+r_{f}\right)$, then $\eta_{r}>F\left(q_{B}\right)$, we have $g\left(q_{B}, v^{*}\right)=p q_{B}-\left(w_{B} q_{B}-B\right)$ $\left(1+r_{B}^{*}\right)-B\left(1+r_{f}\right)-\frac{p}{\eta_{r}} \int_{x_{B}}^{q_{B}} F(x) \mathrm{d} x$. Thus $\frac{\partial g\left(q_{B}, v^{*}\right)}{\partial q_{B}}=p\left(1-\frac{F\left(q_{B}\right)}{\eta_{r}}-\left(1-\frac{F\left(x_{B}\right)}{\eta_{r}}\right) \frac{w_{B}\left(1+r_{f}\right)}{p \bar{F}\left(x_{B}\right)}\right)$. Notice that $\bar{F}\left(q_{B}^{*}\right)=\left(1-\eta_{r}\right)+\left(\eta_{r}-F\left(x_{B}^{*}\right)\right) \frac{w_{B}\left(1+r_{f}\right)}{p \bar{F}\left(x_{B}^{*}\right)}$, thus $\left.\frac{\partial^{2} g\left(q_{B}, v^{*}\right)}{\partial\left(q_{B}\right)^{2}}\right|_{q_{B}=q_{B}^{*}}=-p\left(\frac{F\left(q_{B}^{*}\right)}{\eta_{r}}-\right.$ $\left.\frac{\eta_{r} f\left(q_{B}^{*}\right)\left(1-\eta_{r}\right)}{\left(\eta_{r} \bar{F}\left(x_{B}^{*}\right)\right)^{2} \bar{F}\left(x_{B}^{*}\right)}\left(\frac{w_{B}\left(1+r_{f}\right)}{p}\right)^{2}\right)=-p\left(\frac{\left(1-\eta_{r}\right) h\left(q_{B}^{*}\right)}{\eta_{r}}-\frac{\left(1-\eta_{r}\right) h\left(x_{B}^{*}\right)}{\eta_{r}}\left(\frac{w_{B}\left(1+r_{f}\right)}{p \bar{F}\left(x_{B}^{*}\right)}\right)^{2}-\frac{\left(\eta_{r}-F\left(x_{B}^{*}\right)\right) h\left(q_{B}^{*}\right)}{\eta_{r}} \frac{w_{B}\left(1+r_{f}\right)}{p \bar{F}\left(x_{B}^{*}\right)}\right)<0$.

Therefore, due to the continuity of the retailer's order quantity $q_{B}, q_{B}^{*}$ satisfies $\bar{F}\left(q_{B}^{*}\right)=\left(1-\eta_{r}\right)+\left(\eta_{r}-\right.$ $\left.F\left(x_{B}^{*}\right)\right) \frac{w_{B}\left(1+r_{f}\right)}{p \bar{F}\left(x_{B}^{*}\right)}$, then

$$
q_{B}^{*}=\bar{F}^{-1}\left(\left(1-\eta_{r}\right)+\left(\eta_{r}-F\left(x_{B}^{*}\right)\right) \frac{w_{B}\left(1+r_{f}\right)}{p \bar{F}\left(x_{B}^{*}\right)}\right) .
$$

(ii) The following proofs give that $q_{B}^{*}$ is decreasing in $w_{B}$. Taking the derivative of the implicit function $\bar{F}\left(q_{B}^{*}\right)=\left(1-\eta_{r}\right)+\left(\eta_{r}-F\left(x_{B}^{*}\right)\right) \frac{w_{B}\left(1+r_{f}\right)}{p \bar{F}\left(x_{B}^{*}\right)}$ with respect to $w_{B}$ yields $f\left(q_{B}^{*}\right) \frac{\partial q_{B}^{*}}{\partial w_{B}}=f\left(x_{B}^{*}\right) \frac{\partial x_{B}^{*}}{\partial w_{B}} \frac{\left(1-\eta_{r}\right) w_{B}\left(1+r_{f}\right)}{p\left(\bar{F}\left(x_{B}^{*}\right)\right)^{2}}-$ $\frac{\left(\eta_{r}-F\left(x_{B}^{*}\right)\right)\left(1+r_{f}\right)}{p \bar{F}\left(x_{B}^{*}\right)}$. Then taking the derivative of $\left(w_{B} q_{B}-B\right)\left(1+r_{f}\right)=\left(w_{B} q_{B}-B\right)\left(1+r_{B}^{*}\right)-p \int_{0}^{x_{B}} F(x) \mathrm{d} x$ with respect to $w_{B}$ yields $w_{B}\left(1+r_{f}\right) \frac{\partial q_{B}^{*}}{\partial w_{B}}+q_{B}^{*}\left(1+r_{f}\right)=p \bar{F}\left(x_{B}^{*}\right) \frac{\partial x_{B}^{*}}{\partial w_{B}}$. Based on the above formula, we have

$$
\frac{\partial q_{B}^{*}}{\partial w_{B}}=-\frac{p\left(\bar{F}\left(x_{B}^{*}\right)\right)^{2}\left(1+r_{f}\right)\left(1-\frac{1-\eta_{r}}{\bar{F}\left(x_{B}^{*}\right)}-\frac{\left(1-\eta_{r}\right) w_{B}^{*} q_{B}^{*}\left(1+r_{f}\right)}{p\left(\bar{F}\left(x_{B}^{*}\right)\right)^{2}} h\left(x_{B}^{*}\right)\right)}{\left(p \bar{F}\left(x_{B}^{*}\right)\right)^{2} \bar{F}\left(q_{B}^{*}\right) h\left(q_{B}^{*}\right)-\left(1-\eta_{r}\right)\left(w_{B}\left(1+r_{f}\right)\right)^{2} h\left(x_{B}^{*}\right)} .
$$

Then taking the derivative of $x_{B}^{*}$ with respect to $w_{B}$ yields

$$
\frac{\partial x_{B}^{*}}{\partial w_{B}}=-\frac{p \bar{F}\left(x_{B}^{*}\right) \bar{F}\left(q_{B}^{*}\right)\left(1+r_{f}\right)\left(1-\frac{1-\eta_{r}}{\bar{F}\left(q_{B}^{*}\right)}-q_{B}^{*} h\left(q_{B}^{*}\right)\right)}{\left(p \bar{F}\left(x_{B}^{*}\right)\right)^{2} \bar{F}\left(q_{B}^{*}\right) h\left(q_{B}^{*}\right)-\left(1-\eta_{r}\right)\left(w_{B}\left(1+r_{f}\right)\right)^{2} h\left(x_{B}^{*}\right)} .
$$

Similar to $[7,8]$, we also use proof by contradiction to prove $\frac{\partial q_{B}^{*}}{\partial w_{B}}<0$. Assume $\frac{\partial q_{B}^{*}}{\partial w_{B}} \geq 0$ holds, then both $x_{B}^{*}$ and $\frac{1-\eta_{r}}{\bar{F}\left(q_{B}^{*}\right)}+q_{B}^{*} h\left(q_{B}^{*}\right)$ are increasing in $w_{B}$. Let $w_{0}$ satisfy $\frac{1-\eta_{r}}{\bar{F}\left(q_{B}^{*}\left(w_{0}\right)\right)}+q_{B}^{*}\left(w_{0}\right) h\left(x_{B}^{*}\left(w_{0}\right)\right)=1$. Recall the wholesale price satisfies $c \leq w_{B} \leq \bar{w}_{B}=\frac{p}{1+r_{B}^{*}}$. There exist the following three cases for $w_{B}$.

Case 1. $w_{0} \geq \bar{w}_{B}$, we have $q_{B}^{*}\left(w_{B}\right) h\left(q_{B}^{*}\left(w_{B}\right)\right)+\frac{1-\eta_{r}}{\bar{F}\left(q_{B}^{*}\left(w_{B}\right)\right)} \leq q_{B}^{*}\left(\bar{w}_{B}\right) h\left(q_{B}^{*}\left(\bar{w}_{B}\right)\right)+\frac{1-\eta_{r}}{\bar{F}\left(q_{B}^{*}\left(\bar{w}_{B}\right)\right)} \leq$ $q_{B}^{*}\left(w_{0}\right) h\left(q_{B}^{*}\left(w_{0}\right)\right)+\frac{1-\eta_{r}}{F\left(q_{B}^{*}\left(w_{0}\right)\right)}=1$, thus $\frac{\partial x_{B}^{*}}{\partial w_{B}} \leq 0$. It is a contradiction to our assumption.

Case 2. $c<w_{0}<\bar{w}_{B}=\frac{p}{1+r_{B}^{*}}$, we have $x_{B}^{*}$ being decreasing in $w_{B}$ under $\left[c, w_{0}\right]$. It is also a contradiction to our assumption.

Case 3. $w_{0}=c$, we have $\frac{1-\eta_{r}}{\bar{F}\left(x_{B}^{*}(c)\right)}+\frac{\left(1-\eta_{r}\right) c q_{B}^{*}(c)\left(1+r_{f}\right)}{p\left(\bar{F}\left(x_{B}^{*}(c)\right)\right)^{2}} h\left(x_{B}^{*}(c)\right)<q_{B}^{*}(c) h\left(q_{B}^{*}(c)\right)+\frac{1-\eta_{r}}{\bar{F}\left(q_{B}^{*}(c)\right)}<$ $q_{B}^{*}\left(w_{0}\right) h\left(q_{B}^{*}\left(w_{0}\right)\right)+\frac{1-\eta_{r}}{\bar{F}\left(q_{B}^{*}\left(w_{0}\right)\right)}=1$, thus $\frac{\partial q_{B}^{*}}{\partial w_{B}}<0$. Again, it is a contradiction.

From the above three cases, we find that it is contradictory to the assumptions. Therefore, we obtain $\frac{\partial q_{B}^{*}}{\partial w_{B}}<0$. The following proofs give that $q_{B}^{*}$ is decreasing in $\eta_{r}$. Taking the derivative of the implicit function $\bar{F}\left(q_{B}^{*}\right)=$ $\left(1-\eta_{r}\right)+\left(\eta_{r}-F\left(x_{B}^{*}\right)\right) \frac{w_{B}\left(1+r_{f}\right)}{p \bar{F}\left(x_{B}^{*}\right)}$ with respect to $\eta_{r}$ yields

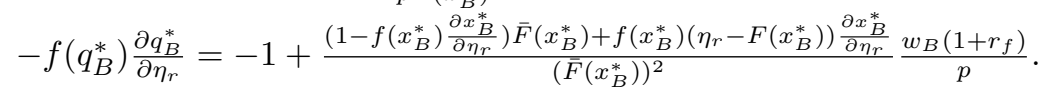

Then taking the derivative of $\left(w_{B} q_{B}-B\right)\left(1+r_{f}\right)=\left(w_{B} q_{B}-B\right)\left(1+r_{B}^{*}\right)-p \int_{0}^{x_{B}} F(x) \mathrm{d} x$ with respect to $\eta_{r}$ yields $w_{B}\left(1+r_{f}\right) \frac{\partial q_{B}^{*}}{\partial \eta_{r}}=p \bar{F}\left(x_{B}^{*}\right) \frac{\partial x_{B}^{*}}{\partial \eta_{r}}$. Based on the above formula, we have $\frac{\partial q_{B}^{*}}{\partial \eta_{r}}=$ $\frac{p \bar{F}\left(x_{B}^{*}\right)\left(p \bar{F}\left(x_{B}^{*}\right)-w_{B}\left(1+r_{f}\right)\right)}{\left(p \bar{F}\left(x_{B}^{*}\right)\right)^{2} \bar{F}\left(q_{B}^{*}\right) h\left(q_{B}^{*}\right)-\left(1-\eta_{r}\right)\left(w_{B}\left(1+r_{f}\right)\right)^{2} h\left(x_{B}^{*}\right)}>0$. 
The following proofs give that $q_{B}^{*}$ is decreasing in $B$. Taking the derivative of the implicit function $\bar{F}\left(q_{B}^{*}\right)=\left(1-\eta_{r}\right)+\left(\eta_{r}-F\left(x_{B}^{*}\right)\right) \frac{w_{B}\left(1+r_{f}\right)}{p \bar{F}\left(x_{B}^{*}\right)}$ with respect to $B$ yields $f\left(q_{B}^{*}\right) \frac{\partial q_{B}^{*}}{\partial B}=\frac{\left(1-\eta_{r}\right) f\left(x_{B}^{*}\right)}{\left(\bar{F}\left(x_{B}^{*}\right)\right)^{2}} \frac{w_{B}\left(1+r_{f}\right)}{p} \frac{\partial x_{B}^{*}}{\partial B}$. Then taking the derivative of $\left(w_{B} q_{B}-B\right)\left(1+r_{f}\right)=\left(w_{B} q_{B}-B\right)\left(1+r_{B}^{*}\right)-p \int_{0}^{x_{B}} F(x) \mathrm{d} x$ with respect to $B$ yields $\left(w_{B} \frac{\partial q_{B}^{*}}{\partial B}-1\right)\left(1+r_{f}\right)=p \bar{F}\left(x_{B}^{*}\right) \frac{\partial x_{B}^{*}}{\partial B}$. Based on the above formula, we have $\frac{\partial q_{B}^{*}}{\partial B}=-\frac{\left(1-\eta_{r}\right) h\left(x_{B}^{*}\right) w_{B}\left(1+r_{f}\right)}{\left(p \bar{F}\left(x_{B}^{*}\right)\right)^{2} \bar{F}\left(q_{B}^{*}\right) h\left(q_{B}^{*}\right)-\left(1-\eta_{r}\right)\left(w_{B}\left(1+r_{f}\right)\right)^{2} h\left(x_{B}^{*}\right)}<0$.

Proof of Proposition 4.2. The supplier's objective function under Mean-CVaR criterion is

$$
U\left(\Pi_{B}\left(w_{B}\right)\right)=\Pi_{B}\left(w_{B}\right)=\left(w_{B}-c\right) q_{B}^{*}\left(1+r_{f}\right) .
$$

To obtain the supplier's optimal wholesale price, we take the first-order derivative of $U\left(\Pi_{B}\left(w_{B}\right)\right)$ with respect to $w_{B}$. Then we have

$$
\frac{\partial U\left(\Pi_{B}\left(w_{B}\right)\right)}{\partial w_{B}}=\frac{c\left(1+r_{f}\right)}{\mu_{1}\left(w_{B}\right)} \frac{\partial q_{B}^{*}}{\partial w_{B}}\left(\eta_{r}-F\left(q_{B}^{*}\right)-q_{B}^{*} f\left(q_{B}^{*}\right)-\frac{c\left(1+r_{f}\right) \mu_{1}\left(w_{B}\right)}{p}\right),
$$

where $\mu_{1}\left(w_{B}\right)=1-\frac{1-\eta_{r}}{\bar{F}\left(x_{B}^{*}\right)}-\frac{\left(1-\eta_{r}\right) w_{B} q_{B}^{*}\left(1+r_{f}\right)}{p\left(\bar{F}\left(x_{B}^{*}\right)\right)^{2}} h\left(x_{B}^{*}\right)$. $\frac{\partial U\left(\Pi_{B}\left(w_{B}\right)\right)}{\partial w_{B}}$ depends on $\eta_{r}-F\left(q_{B}^{*}\right)-\frac{c\left(1+r_{f}\right) \mu_{1}\left(w_{B}\right)}{p}$. When $w_{B} \leq w_{0}$, we obtain $\frac{\partial U\left(\Pi_{B}\left(w_{B}\right)\right)}{\partial w_{B}}>0$, the supplier's profit is increasing in $w_{B}$. When $w_{B}>w_{0}$, we have $\eta_{r}-F\left(q_{B}^{*}\right)-q_{B}^{*} f\left(q_{B}^{*}\right)>0$. Then the following proves that $u\left(w_{B}\right)=\eta_{r}-F\left(q_{B}^{*}\right)-q_{B}^{*} f\left(q_{B}^{*}\right)-\frac{c\left(1+r_{f}\right) \mu_{1}\left(w_{B}\right)}{p}$ is increasing in $w_{B}$.

$$
\begin{aligned}
\frac{\partial u\left(w_{B}\right)}{\partial w_{B}}= & \left(-2 f\left(q_{B}^{*}\right)+f\left(q_{B}^{*}\right) H\left(q_{B}^{*}\right)-q_{B}^{*} \bar{F}\left(q_{B}^{*}\right) h^{\prime}\left(q_{B}^{*}\right)\right) \frac{\partial q_{B}^{*}}{\partial w_{B}}+\frac{c\left(1+r_{f}\right)}{p}\left(2 \frac{1-\eta_{r}}{\bar{F}\left(x_{B}^{*}\right)} h\left(x_{B}^{*}\right)\right. \\
& \left.+\frac{\left(1-\eta_{r}\right) w_{B} q_{B}^{*}\left(1+r_{f}\right)}{p\left(\bar{F}\left(x_{B}^{*}\right)\right)^{2}} h^{\prime}\left(x_{B}^{*}\right)+\frac{2\left(1-\eta_{r}\right) w_{B} q_{B}^{*}\left(1+r_{f}\right) f\left(x_{B}^{*}\right)}{p\left(\bar{F}\left(x_{B}^{*}\right)\right)^{3}} h\left(x_{B}^{*}\right)\right) \\
& >\frac{\partial q_{B}^{*}}{\partial w_{B}}\left(-f\left(q_{B}^{*}\right)\left(2-H\left(q_{B}^{*}\right)\right)-q_{B}^{*} \bar{F}\left(q_{B}^{*}\right) h^{\prime}\left(q_{B}^{*}\right)+\frac{\left(1-\eta_{r}\right) w_{B} q_{B}^{*} c\left(1+r_{f}\right)^{2}}{\left(p \bar{F}\left(x_{B}^{*}\right)\right)^{2}} h^{\prime}\left(x_{B}^{*}\right)\right. \\
& \left.+\frac{c\left(1+r_{f}\right)}{p}\left(2 \frac{1-\eta_{r}}{\bar{F}\left(x_{B}^{*}\right)}+\frac{2\left(1-\eta_{r}\right) w_{B} q_{B}^{*}\left(1+r_{f}\right) f\left(x_{B}^{*}\right)}{p\left(\bar{F}\left(x_{B}^{*}\right)\right)^{3}}\right) h\left(x_{B}^{*}\right)\right) \\
& >\frac{\partial q_{B}^{*}}{\partial w_{B}}\left(-2 \frac{\eta_{r}-F\left(x_{B}^{*}\right)}{\bar{F}\left(x_{B}^{*}\right)}-\frac{\eta_{r}-F\left(x_{B}^{*}\right)}{\left(\bar{F}\left(x_{B}^{*}\right)\right)^{2}}+H\left(q_{B}^{*}\right)+\frac{2 w_{B} q_{B}^{*}\left(1+r_{f}\right) f\left(x_{B}^{*}\right)}{p\left(\bar{F}\left(x_{B}^{*}\right)\right)^{2}}\right) h\left(x_{B}^{*}\right) \\
& >\frac{\partial q_{B}^{*}}{\partial w_{B}}\left(-2 \frac{\eta_{r}-F\left(x_{B}^{*}\right)}{\bar{F}\left(x_{B}^{*}\right)}-\frac{\eta_{r}-F\left(x_{B}^{*}\right)}{\left(\bar{F}\left(x_{B}^{*}\right)\right)^{2}}+2 \frac{\eta_{r}-F\left(q_{B}^{*}\right)}{\bar{F}\left(q_{B}^{*}\right)}-\frac{\eta_{r}-F\left(q_{B}^{*}\right)}{\left(\bar{F}\left(q_{B}^{*}\right)\right)^{2}}\right) h\left(x_{B}^{*}\right)>0
\end{aligned}
$$

We get $u\left(w_{B}\right)$ is increasing in $w_{B}$. When $w_{B}=c$, then $\eta_{r}-F\left(q_{B}^{*}(c)\right)-q_{B}^{*} f\left(q_{B}^{*}(c)\right)<\frac{c\left(1+r_{f}\right) \mu_{1}(c)}{p}$.

When $w_{B}=\frac{p}{1+r_{B}^{*}}$, then $\eta_{r}-F\left(q_{B}^{*}\left(\frac{p}{1+r_{B}^{*}}\right)\right)-q_{B}^{*} f\left(q_{B}^{*}\left(\frac{p}{1+r_{B}^{*}}\right)\right)>\frac{c\left(1+r_{f}\right) \mu_{1}\left(\frac{p}{1+r_{B}^{*}}\right)}{p}$.

Further, $w_{B}^{*}$ satisfies $\eta_{r}-F\left(q_{B}^{*}\right)-q_{B}^{*} f\left(q_{B}^{*}\right)=\frac{c\left(1+r_{f}\right) \mu_{1}\left(w_{B}^{*}\right)}{p}$.

Based on $q_{B}^{*}$, then we obtain $w_{B}^{*}=\frac{p q_{B}^{*} f\left(q_{B}^{*}\right)+\mu_{1}\left(w_{B}^{*}\right) c\left(1+r_{f}\right)}{\left(\eta_{r}-F\left(x_{B}^{*}\right)\right)\left(1+r_{f}\right)} \bar{F}\left(x_{B}^{*}\right)$.

Proof of Proposition 4.3. (i) Under TCF, the risk-averse retailer's objective function under CVaR criterion is

$$
\mathrm{CVaR}_{\eta_{r}}\left(\pi_{T}\left(q_{T}, x\right)\right)=\max _{v \in R}\left\{v-\frac{1}{\eta_{r}} E\left[v-\pi_{T}\left(q_{T}, x\right)\right]^{+}\right\}=\max _{v \in R}\left\{g\left(q_{T}, v\right)\right\},
$$


then $q_{T}^{*}=\arg \max _{q_{T}>0}\left\{\mathrm{CVaR}_{\eta_{r}}\left(\pi_{T}\left(q_{T}, x\right)\right)\right\}$. Similar to the proof of Proposition 4.1, $q_{T}^{*}$ satisfies $\bar{F}\left(q_{T}^{*}\right)=\left(1-\eta_{r}\right)+\left(\eta_{r}-F\left(x_{T}^{*}\right)\right) \frac{w_{T}\left(1+r_{T}\right)}{p}$, then the retailer's optimal order quantity

$$
q_{T}^{*}=\bar{F}^{-1}\left(\left(1-\eta_{r}\right)+\left(\eta_{r}-F\left(x_{T}^{*}\right)\right) \frac{w_{T}\left(1+r_{T}\right)}{p}\right) .
$$

(ii) The following proofs give that $q_{T}^{*}$ is decreasing in $w_{T}$. Taking the derivative of the implicit function $\bar{F}\left(q_{T}^{*}\right)=\left(1-\eta_{r}\right)+\left(\eta_{r}-F\left(x_{T}^{*}\right)\right) \frac{w_{T}\left(1+r_{T}\right)}{p}$ with respect to $w_{T}$ yields $f\left(q_{T}^{*}\right) \frac{\partial q_{T}^{*}}{\partial w_{T}}=f\left(x_{T}^{*}\right) \frac{\partial x_{T}^{*}}{\partial w_{T}} \frac{w_{T}\left(1+r_{T}\right)}{p}-\frac{\left(\eta_{r}-F\left(x_{T}^{*}\right)\right)\left(1+r_{T}\right)}{p}$. Hence, we get

$$
\frac{\partial q_{T}^{*}}{\partial w_{T}}=-\frac{p \bar{F}\left(x_{T}^{*}\right)\left(1+r_{T}\right)\left(1-\frac{1-\eta_{r}}{\bar{F}\left(x_{T}^{*}\right)}-\frac{w_{T}^{*} q_{T}^{*}\left(1+r_{T}\right)}{p} h\left(x_{T}^{*}\right)\right)}{p^{2} \bar{F}\left(q_{T}^{*}\right) h\left(q_{T}^{*}\right)-\left(w_{T}\left(1+r_{T}\right)\right)^{2} \bar{F}\left(x_{T}^{*}\right) h\left(x_{T}^{*}\right)} .
$$

Moreover, taking the derivative of $x_{T}^{*}$ with respect to $w_{T}$ yields

$$
\frac{\partial x_{T}^{*}}{\partial w_{T}}=-\frac{p \bar{F}\left(q_{T}^{*}\right)\left(1+r_{T}\right)\left(1-\frac{1-\eta_{r}}{\bar{F}\left(q_{T}^{*}\right)}-H\left(q_{T}^{*}\right)\right)}{p^{2} \bar{F}\left(q_{T}^{*}\right) h\left(q_{T}^{*}\right)-\left(w_{T}\left(1+r_{T}\right)\right)^{2} \bar{F}\left(x_{T}^{*}\right) h\left(x_{T}^{*}\right)} .
$$

Similar to the proof the Proposition 4.1, we also use proof by contradiction to prove $\frac{\partial q_{T}^{*}}{\partial w_{T}}<0$. Assume $\frac{\partial q_{T}^{*}}{\partial w_{T}} \geq 0$ holds, similar to the proof of Proposition 4.1, we find that it is contradictory to the assumptions. Therefore, we obtain $\frac{\partial q_{T}^{*}}{\partial w_{T}}<0$.

Taking the derivative of the optimal order quantity $q_{T}^{*}$ with respect to $\eta_{r}$, we obtain

$$
\frac{\partial q_{T}^{*}}{\partial \eta_{r}}=\frac{p^{2}-w_{T}\left(1+r_{T}\right)}{p^{2} \bar{F}\left(q_{T}^{*}\right) h\left(q_{T}^{*}\right)-\left(w_{T}\left(1+r_{T}\right)\right)^{2} \bar{F}\left(x_{T}^{*}\right) h\left(x_{T}^{*}\right)}>0 .
$$

Therefore, $q_{T}^{*}$ is increasing in $\eta_{r}$.

Taking the derivative of the optimal order quantity $q_{T}^{*}$ with respect to $B$, we obtain that

$$
\frac{\partial q_{T}^{*}}{\partial B}=-\frac{p\left(1+r_{T}\right) \bar{F}\left(x_{T}^{*}\right) h\left(x_{T}^{*}\right)}{p^{2} \bar{F}\left(q_{T}^{*}\right) h\left(q_{T}^{*}\right)-\left(w_{T}\left(1+r_{T}\right)\right)^{2} \bar{F}\left(x_{T}^{*}\right) h\left(x_{T}^{*}\right)}<0 .
$$

Therefore, $q_{T}^{*}$ is decreasing in $B$.

Proof of Proposition 4.4. Under TCF, the supplier's objective function under Mean-CVaR criterion is

$$
\begin{aligned}
U\left(\Pi_{T}\left(w_{T}\right)\right)= & \frac{1-\lambda_{s}}{1-\eta_{s}}\left(\left(w_{T} q_{T}^{*}-B\right)\left(1+r_{T}\right)+B\left(1+r_{f}\right)-c q_{T}^{*}\left(1+r_{f}\right)-p \int_{0}^{x_{T}^{*}} F(x) \mathrm{d} x\right) \\
& +\frac{\lambda_{s}-\eta_{s}}{1-\eta_{s}}\left\{\begin{array}{lll}
p F^{-1}\left(\eta_{s}\right)+B\left(1+r_{f}\right)-c q_{T}^{*}\left(1+r_{f}\right)-\frac{p}{\eta_{s}} \int_{0}^{F^{-1}\left(\eta_{s}\right)} F(x) \mathrm{d} x, & \text { if } & \eta_{s}<F\left(x_{T}^{*}\right) \\
\left(w_{T} q_{T}^{*}-B\right)\left(1+r_{T}\right)+B\left(1+r_{f}\right)-c q_{T}^{*}\left(1+r_{f}\right)-\frac{p}{\eta_{s}} \int_{0}^{x_{T}^{*}} F(x) \mathrm{d} x, & \text { if } & \eta_{s} \geq F\left(x_{T}^{*}\right) .
\end{array}\right.
\end{aligned}
$$

When $\eta_{s}<F\left(x_{T}^{*}\right)$, we get

$$
\frac{\partial U\left(\Pi_{T}\left(w_{T}\right)\right)}{\partial w_{T}}=p \frac{\partial q_{T}^{*}}{\partial w_{T}}\left(\frac{1-\lambda_{s}}{1-\eta_{s}} \bar{F}\left(q_{T}^{*}\right) \mu_{2}\left(w_{T}\right)-\frac{c\left(1+r_{f}\right)}{p}\right)
$$




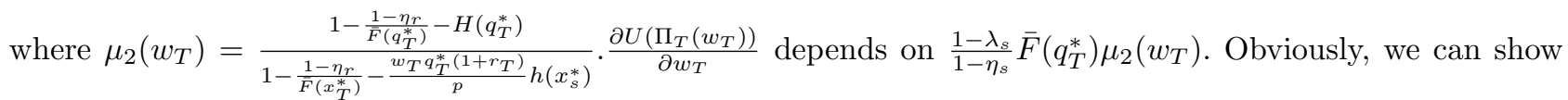
that $\frac{1-\lambda_{s}}{1-\eta_{s}} \bar{F}\left(q_{T}^{*}\right)$ is increasing in $w_{T}$. In this paper, we assume demand distributions with increasing and convex failure rates, $h^{\prime}\left(\xi_{2}\right) \geq h^{\prime}\left(\xi_{1}\right) \geq 0$ for $\xi_{2} \geq \xi_{1} \geq 0$ similar to [21, 29], e.g., uniform, exponential, power and Weibull with parameter meet the assumption. Similar to the proof of Proposition 4.2, we obtain show that $\mu_{2}\left(w_{T}\right)$ is increasing in $w_{T} . \underline{\mathrm{w}}_{T}$ is determined by $\frac{1-\lambda_{s}}{1-\eta_{s}} \bar{F}\left(q_{T}^{*}\right) \mu_{2}\left(\underline{\mathrm{w}}_{T}\right)=\frac{c\left(1+r_{f}\right)}{p}$, then, $\hat{w}_{T}=\frac{\left(1-\eta_{s}\right) c\left(1+r_{f}\right)-p\left(1-\eta_{r}\right)\left(1-\lambda_{s}\right) \mu_{2}\left(\hat{w}_{T}\right)}{\left(\eta_{r}-F\left(x_{T}^{*}\right)\right)\left(1+r_{T}\right)\left(1-\lambda_{s}\right) \mu_{2}\left(\hat{w}_{T}\right)}$. In summary, $w_{T}^{*}=\min \left\{\max \left\{\underline{\mathrm{w}}_{T}, \hat{w}_{T}\right\}, \bar{w}_{T}\right\}$.

When $\eta_{s} \geq F\left(x_{T}^{*}\right)$, we get

$$
\frac{\partial U\left(\Pi_{T}\left(w_{T}\right)\right)}{\partial w_{T}}=p \frac{\partial q_{T}^{*}}{\partial w_{T}}\left(\frac{\eta_{s}-\lambda_{s} F\left(x_{T}^{*}\right)}{\eta_{s} \bar{F}\left(x_{T}^{*}\right)} \bar{F}\left(q_{T}^{*}\right) \mu_{2}\left(w_{T}\right)-\frac{c\left(1+r_{f}\right)}{p}\right),
$$

$\frac{\partial U\left(\Pi_{T}\left(w_{T}\right)\right)}{\partial w_{T}}$ depends on $\frac{\eta_{s}-\lambda_{s} F\left(x_{T}^{*}\right)}{\eta_{s} \bar{F}\left(x_{T}^{*}\right)} \bar{F}\left(q_{T}^{*}\right) \mu_{2}\left(w_{T}\right)$. We show $\frac{\eta_{s}-\lambda_{s} F\left(x_{T}^{*}\right)}{\eta_{s} \bar{F}\left(x_{T}^{*}\right)} \bar{F}\left(q_{T}^{*}\right)$ is increasing with $w_{T}$, then obtain $\frac{\eta_{s}-\lambda_{s} F\left(x_{T}^{*}\right)}{\eta_{s} \bar{F}\left(x_{T}^{*}\right)} \bar{F}\left(q_{T}^{*}\right) \mu_{2}\left(w_{T}\right)$ is increasing in $w_{T}$. Hence, $\tilde{w}_{T}$ is determined by $\frac{\eta_{s}-\lambda_{s} F\left(x_{T}^{*}\right)}{\eta_{s} \bar{F}\left(x_{T}^{*}\right)} \bar{F}\left(q_{T}^{*}\right) \mu_{2}\left(\tilde{w}_{T}\right)=\frac{c\left(1+r_{f}\right)}{p}$, then $\tilde{w}_{T}=\frac{\eta_{s} F\left(x_{T}^{*}\right) c\left(1+r_{f}\right)-p\left(1-\eta_{r}\right)\left(\eta_{s}-\lambda_{s} F\left(x_{T}^{*}\right)\right) \mu_{2}\left(\tilde{w}_{T}\right)}{\left(\eta_{r}-F\left(x_{T}^{*}\right)\right)\left(1+r_{T}\right)\left(\eta_{s}-\lambda_{s} F\left(x_{T}^{*}\right)\right) \mu_{2}\left(\tilde{w}_{T}\right)}$. In summary, $w_{T}^{*}=\min \left\{\max \left\{\underline{\underline{w}}_{T}, \tilde{w}_{T}\right\}, \bar{w}_{T}\right\}$.

Proof of Proposition 5.1. Under BCF, with a wholesale price contract, the supplier with different risk preferences does not bear any commercial risks, the supplier's objective function under Mean-CVaR criterion is

$$
\begin{aligned}
U\left(\Pi_{B}\left(w_{B}^{*}\right)\right) & =\left(w_{B}^{*}-c\right) q_{B}^{*}\left(1+r_{f}\right) \\
& =p E\left[\min \left(x, x_{B}^{*}\right)\right]-c q_{B}^{*}\left(1+r_{f}\right)+B\left(1+r_{f}\right) .
\end{aligned}
$$

Under TCF, when $\eta_{s}<F\left(x_{T}^{*}\right)$, the supplier's objective function under Mean-CVaR criterion is

$$
\begin{aligned}
U\left(\Pi_{T}\left(w_{T}^{*}\right)\right)= & \frac{1-\lambda_{s}}{1-\eta_{s}}\left(\left(w_{T}^{*} q_{T}^{*}-B\right)\left(1+r_{T}\right)+B\left(1+r_{f}\right)-c q_{T}^{*}\left(1+r_{f}\right)-p \int_{0}^{x_{T}^{*}} F(x) \mathrm{d} x\right) \\
& +\frac{\lambda_{s}-\eta_{s}}{1-\eta_{s}}\left(p F^{-1}\left(\eta_{s}\right)+B\left(1+r_{f}\right)-c q_{T}^{*}\left(1+r_{f}\right)-\frac{p}{\eta_{s}} \int_{0}^{F^{-1}\left(\eta_{s}\right)} F(x) \mathrm{d} x\right) .
\end{aligned}
$$

According to Proposition 4.4, taking the derivative of the above formula with respect to $\lambda_{s}$ yields

$$
\begin{aligned}
\frac{\partial U\left(\Pi_{T}\left(w_{T}\right)\right)}{\partial \lambda_{s}}= & \frac{-1}{1-\eta_{s}}\left(\left(w_{T} q_{T}^{*}-B\right)\left(1+r_{T}\right)-p \int_{0}^{x_{T}^{*}} F(x) \mathrm{d} x\right. \\
& \left.-p F^{-1}\left(\eta_{s}\right)+\frac{p}{\eta_{s}} \int_{0}^{F^{-1}\left(\eta_{s}\right)} F(x) \mathrm{d} x\right)<0 .
\end{aligned}
$$

Hence, $U\left(\Pi_{T}\left(w_{T}\right)\right)$ is decreasing in $\lambda_{s}$. When $\lambda_{s}=\eta_{s}$, that is, the supplier is risk-neutral.

Similar to [15], we suppose that the interest rate $r_{T}$ satisfies $r_{T}=r_{B}^{*}$. Under TCF, according to Propositions 4.1 and 4.3 ,

we get $q_{T}^{*}\left(w_{B}^{*}, r_{B}^{*}\right)>q_{B}^{*}$. From the above discussion, we have $x_{T}\left(w_{B}^{*}\right)=\frac{\left.w_{T} q_{T}-B\right)\left(1+r_{T}\right)}{p}=$ $\frac{\left(w_{B}^{*} q_{T}^{*}\left(w_{B}^{*}, r_{B}^{*}\right)-B\right)\left(1+r_{B}^{*}\right)}{p}$,

then $x_{T}^{*}>x_{B}^{*}$. The supplier's objective function under Mean-CVaR criterion is

$$
U\left(\Pi_{T}\left(w_{B}^{*}, r_{B}^{*}\right)\right)=p E\left[\min \left(x, x_{T}^{*}\right)\right]-c q_{T}^{*}\left(1+r_{f}\right)+B\left(1+r_{f}\right) .
$$


Thus

$$
\begin{aligned}
U\left(\Pi_{T}\left(w_{B}^{*}, r_{B}^{*}\right)\right)-U\left(\Pi_{B}\left(w_{B}^{*}, r_{B}^{*}\right)\right) \\
=p E\left[\min \left(x, x_{T}\left(w_{B}^{*}\right)\right)\right]-c q_{T}^{*}\left(1+r_{f}\right)-p E\left[\min \left(x, x_{B}^{*}\right)\right]-c q_{B}^{*}\left(1+r_{f}\right) \\
=w_{B}^{*}\left(q_{T}^{*}-q_{B}^{*}\right)\left(1+r_{B}^{*}\right)-c\left(q_{T}^{*}-q_{B}^{*}\right)\left(1+r_{f}\right)-p \int_{x_{B}^{*}}^{x_{T}\left(w_{B}^{*}\right)} F(x) \mathrm{d} x \\
\quad>\left(q_{T}^{*}-q_{B}^{*}\right)\left(w_{B}^{*} \bar{F}\left(x_{T}\left(w_{B}^{*}\right)\right)\left(1+r_{B}^{*}\right)-c\left(1+r_{f}\right)\right) \\
\quad>\left(q_{T}^{*}-q_{B}^{*}\right)\left(p \bar{F}\left(q_{T}^{*}\right)-c\left(1+r_{f}\right)\right)>0 .
\end{aligned}
$$

Then $\lim _{\lambda_{s}=\eta_{s}} U\left(\Pi_{T}\left(w_{B}^{*}, r_{B}^{*}\right)\right)>U\left(\Pi_{B}\left(w_{B}^{*}, r_{B}^{*}\right)\right)$, thus $\lim _{\lambda_{s}=\eta_{s}} U\left(\Pi_{T}\left(w_{T}^{*}\right)\right)>U\left(\Pi_{B}\left(w_{B}^{*}\right)\right)$.

There exists a $\bar{\lambda}_{s}\left(\eta_{s}\right)=1-\left(1-\eta_{s}\right) \frac{\left(w_{B}^{*} q_{B}^{*}-c q_{B}^{*}-B+c q_{T}^{*}\right)\left(1+r_{f}\right)-p F^{-1}\left(\eta_{s}\right)+\frac{p}{\eta_{s}} \int_{0}^{F^{-1}\left(\eta_{s}\right)} F(x) \mathrm{d} x}{\left(w_{T}^{*} q_{T}^{*}-B\right)\left(1+r_{T}\right)-p \int_{0}^{x_{T}^{*}} F(x) \mathrm{d} x-p F^{-1}\left(\eta_{s}\right)+\frac{p}{\eta_{s}} \int_{0}^{F^{-1}\left(\eta_{s}\right)} F(x) \mathrm{d} x}$ satisfies $U\left(\Pi_{T}\left(w_{T}^{*}\right)\right)=U\left(\Pi_{B}\left(w_{B}^{*}\right)\right)$.

When $\eta_{s} \geq F\left(x_{T}^{*}\right)$, the supplier's objective function under Mean-CVaR criterion is

$$
U\left(\Pi_{T}\left(w_{T}^{*}\right)\right)=\left(w_{T}^{*} q_{T}^{*}-B\right)\left(1+r_{T}\right)+B\left(1+r_{f}\right)-c q_{T}^{*}\left(1+r_{f}\right)-p \frac{\lambda_{s}}{\eta_{s}} \int_{0}^{x_{T}^{*}} F(x) \mathrm{d} x .
$$

According to Proposition 4.4, taking the derivative of the above formula with respect to $\lambda_{s}$ yields $\frac{\partial U\left(\Pi_{T}\left(w_{T}\right)\right)}{\partial \lambda_{s}}=$ $-\frac{p}{\eta_{s}} \int_{0}^{x_{T}^{*}} F(x) \mathrm{d} x<0$. Hence, $U\left(\Pi_{T}\left(w_{T}^{*}\right)\right)$ is decreasing in $\lambda_{s}$. When $\lambda_{s}=\eta_{s}$, similar with the above discussion, we obtain $\lim _{\lambda_{s}=\eta_{s}} U\left(\Pi_{T}\left(w_{T}^{*}\right)\right)>U\left(\Pi_{B}\left(w_{B}^{*}\right)\right)$. There exists a supplier's risk preference threshold $\bar{\lambda}_{s}\left(\eta_{s}\right)=\eta_{s} \frac{\left(w_{T}^{*} q_{T}^{*}-B\right)\left(1+r_{T}\right)-c\left(q_{T}^{*}-q_{B}^{*}\right)\left(1+r_{f}\right)-\left(w_{B}^{*} q_{B}^{*}-B\right)\left(1+r_{f}\right)}{p \int_{0}^{x_{T}^{*}} F(x) \mathrm{d} x}$ satisfies $U\left(\Pi_{T}\left(w_{T}^{*}\right)\right)=U\left(\Pi_{B}\left(w_{B}^{*}\right)\right)$.

In summary, if $\lambda_{s} \in\left[0, \bar{\lambda}_{s}\right)$, TCF is unique financing equilibrium; if $\lambda_{s} \in\left[\bar{\lambda}_{s}, 1\right]$ the members prefer BCF, where $\bar{\lambda}_{s}=\min \left(\bar{\lambda}_{s}\left(\eta_{s}\right), 1\right)$ and

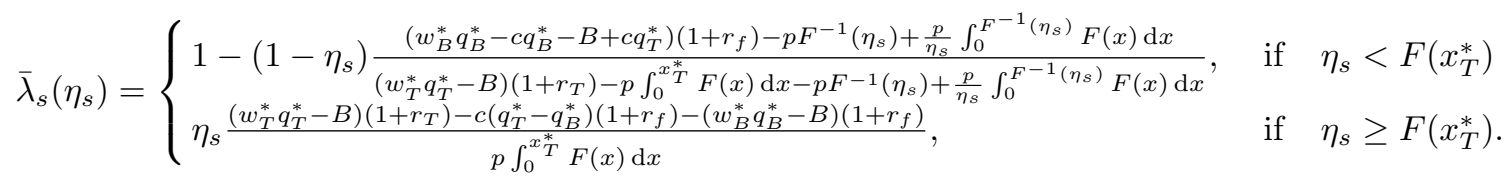

\section{REFERENCES}

[1] S. Asian and X. Nie, Coordination in supply chains with uncertain demand and disruption risks: existence, analysis, and insights. IEEE Trans. Syst. Man. Cybern.: Syst. 44 (2014) 1139-1154.

[2] M. Ayyagari, T. Beck and A. Demirguc-Kunt, Small and medium enterprises across the globe. Small Bus. Econ. 29 (2007) 415-434.

[3] L. Bo, C. Ping, Q. Li and W. Wang, Dual-channel supply chain pricing decisions with a risk-averse retailer. Int. J. Prod. Res. 52 (2014) 7132-7147.

[4] L. Bo, A. Si-Min and S. Dong-Ping, Selection of financing strategies with a risk-averse supplier in a capital-constrained supply chain. Transp. Res. E-Log. 118 (2018) 163-183.

[5] G. Cai, X. Chen and Z. Xiao, The roles of bank and trade credits: theoretical analysis and empirical evidence. Prod. Oper. Manage. 23 (2014) 583-598.

[6] H.L. Chang and B.-D. Rhee, Trade credit for supply chain coordination. Eur. J. Oper. Res. 214 (2011) $136-146$.

[7] X. Chen, A model of trade credit in a capital-constrained distribution channel. Int. J. Prod. Econ. 159 (2015) $347-357$.

[8] X. Chen and A. Wang, Trade credit contract with limited liability in the supply chain with budget constraints. Ann. Oper. Res. 196 (2012) 153-165.

[9] J. Chen and Y.-W. Zhou, A risk-averse newsvendor model under trade credit contract with CVaR. Asia. Pac. J. Oper. Res. 34 (2017) 1740012. 
[10] Y. Chen, M. Xu and Z.G. Zhang, Technical note: a risk-averse newsvendor model under the CVaR criterion. Oper. Res. $\mathbf{5 7}$ (2009) 1040-1044.

[11] X. Chen, S. Shum and D. Simchi-Levi, Stable and coordinating contracts for a supply chain with multiple risk-averse suppliers. Prod. Oper. Manage. 23 (2014) 379-392.

[12] Z. Chen, K. Yuan and S. Zhou, Supply chain coordination with trade credit under the CVaR criterion. Int. J. Prod. Res. 57 (2019) 3538-3553.

[13] T.-M. Choi, Handbook of Newsvendor Problems: Models, Extensions and Applications. Vol. 176 of International Series in Operations Research \& Management Science. Springer, New York, NY (2012).

[14] J. Cong, T. Pang and H. Peng, Optimal strategies for capital constrained low-carbon supply chain under yield uncertainty. J. Clean. Prod. 256 (2020) 120339.

[15] B.C. Giri and S. Sharma, Optimal ordering policy for an inventory system with linearly increasing demand and allowable shortages under two levels trade credit financing. Oper. Res. Ger. 16 (2016) 25-50.

[16] S. Guo and N. Liu, Influences of supply chain finance on the mass customization program: risk attitudes and cash flow shortage. Int. Trans. Oper. Res. 27 (2020) 2396-2421.

[17] W. Jammernegg and P. Kischka, Risk-averse and risk-taking newsvendors: a conditional expected value approach. Rev. Manage. Sci. 1 (2007) 93-110.

[18] B. Jing, X. Chen and G.G. Cai, Equilibrium financing in a distribution channel with capital constraint. Prod. Oper. Manage. 21 (2012) 1090-1101.

[19] M.N. Katehakis, B. Melamed and J. Shi, Cash-flow based dynamic inventory management. Prod. Oper. Manage. 25 (2016) $1558-1575$.

[20] T. Koller, D. Lovallo and Z. Williams, Overcoming a bias against risk. Tech. Rep. 4 (2012) 15-17.

[21] P. Kouvelis and W. Zhao, The newsvendor problem and price-only contract when bankruptcy costs exist. Prod. Oper. Manage. 20 (2011) 921-936.

[22] P. Kouvelis and W. Zhao, Financing the newsvendor: supplier vs. bank, and the structure of optimal trade credit contracts. Oper. Res. 60 (2012) 566-580.

[23] P. Kouvelis and W. Zhao, Supply chain contract design under financial constraints and bankruptcy costs. Manage. Sci. 62 (2016) 2341-2357.

[24] J. Li, J. Chen and S. Wang, Risk Management of Supply and Cash Flows in Supply Chains. Vol. 165 of International Series in Operations Research \&S Management Science. Springer, New York, NY (2011).

[25] J.W. Payne, J.L. Dan and R. Crum, Translation of gambles and aspiration level effects in risky choice behavior. Manage. Sci. 26 (1980) 1039-1060.

[26] H. Peng and T. Pang, Financing strategies for a capital-constrained supplier under yield uncertainty. J. Ind. Manage. Optim. 16 (2020) 887-909.

[27] J. Qin, L. Ren, L. Xia, Z. Wang and H. Chang, Pricing strategies for dual-channel supply chains under a trade credit policy. Int. Trans. Oper. Res. 27 (2020) 2469-2508.

[28] R. Rockafellar and S. Uryasev, Optimization of conditional value-at-risk. J. Risk 2 (2000) $21-42$.

[29] N. Rudi and H. Groenevelt, Essays in interfaces of operations and finance in supply chains, dissertations \& theses. University of Rochester, NY (2009).

[30] B. Shen, T.M. Choi, Y. Wang and L. Chris, The coordination of fashion supply chains with a risk averse supplier under markdown money policy. IEEE Trans. Syst. Man. Cybern.: Syst. 43 (2013) 266-276.

[31] A.A. Tsay, Risk sensitivity in distribution channel partnerships: implications for manufacturer return policies. J. Retail. $\mathbf{7 8}$ (2002) 147-160.

[32] M. Wu, S.X. Zhu and R.H. Teunter, A risk-averse competitive newsvendor problem under the CVaR criterion. Int. J. Prod. Econ. 156 (2014) 13-23.

[33] Y. Xie, H. Wang and H. Lu, Coordination of supply chains with a retailer under the Mean-CVaR criterion. IEEE Trans. Syst. Man. Cybern.: Syst. 48 (2016) 1039-1053.

[34] X. Xinsheng, M. Zhiqing, S. Rui, J. Min and J. Ping, Optimal decisions for the loss-averse newsvendor problem under CVaR. Int. J. Prod. Econ. 164 (2015) 146-159.

[35] N. Yan, C. Liu, L. Ye and B. Sun, Effects of risk aversion and decision preference on equilibriums in supply chain finance incorporating bank credit with credit guarantee. Appl. Stoch. Models Bus. 33 (2017) 602-625.

[36] N. Yan, T. Tong and H. Dai, Capital-constrained supply chain with multiple decision attributes: decision optimization and coordination analysis. J. Ind. Manage. Optim. 15 (2018) 1831.

[37] H. Yang, L. Chu and H. Wan, Advertising and pricing policies in a two-echelon supply chain with a capital-constrained retailer. RAIRO: OR 53 (2019) 1331-1342.

[38] F. Ye, Q. Lin and Y. Li, Coordination for contract farming supply chain with stochastic yield and demand under CVaR criterion. Oper. Res. Ger. 20 (2020) 369-397.

[39] X. Yuan, G. Bi, B. Zhang and Y. Yu, Option contract strategies with risk-aversion and emergency purchase. Int. Trans. Oper. Res. 27 (2020) 3079-3103.

[40] W. Zhou, J. Li and Y. Zhong, Cooperative advertising and ordering policies in a two-echelon supply chain with risk-averse agents. Omega 75 (2018) 97-117. 